\title{
Natural-Color Green Diamonds: A Beautiful Conundrum
}

Christopher M. Breeding, Sally Eaton-Magaña, and James E. Shigley

Among fancy-color diamonds, natural-color green stones with saturated hues are some of the rarest and most sought after. These diamonds are colored either by simple structural defects produced by radiation exposure or by more complex defects involving nitrogen, hydrogen, or nickel impurities. Most of the world's current production of fine natural green diamonds comes from South America or Africa. Laboratory irradiation treatments have been used commercially since the late 1940 s to create green color in diamond and closely mimic the effects of natural radiation exposure, causing tremendous difficulty in gemological identification. Compounding that problem is a distinct paucity of published information on these diamonds due to their rarity. Four different coloring mechanisms-absorption by GR1 defects due to radiation damage, green luminescence from $\mathrm{H} 3 \mathrm{de}$ fects, and absorptions caused by hydrogen- and nickel-related defects—can be identified in green diamonds. Careful microscopic observation, gemological testing, and spectroscopy performed at GIA over the last decade allows an unprecedented characterization of these beautiful natural stones. By leveraging GIA's vast database of diamond information, we have compiled data representative of tens of thousands of samples to offer a look at natural green diamonds that has never before been possible.

$\mathrm{F}$ ancy-color diamonds are among the most highly valued of gemstones due to their beauty and rarity. Interestingly, the rarest of diamond colors correlate with the three most popular choices for favorite color, in general-green, blue, and pink to red. The unique set of conditions in nature that produce the structural imperfections (defects in the lattice of carbon atoms; see Shigley and Breeding, 2013) responsible for the most vibrant hues of green, blue, and pink/red diamonds are so uncommon that many people are not even aware these stones exist. Over the last ten years, diamonds with these natural color components comprised less than $0.4 \%$ of all diamonds submitted to GIA's laboratories worldwide (including both fancy-color and those on the D-Z scale). Pure hues of green, blue, or red are even rarer, accounting for less than $0.07 \%$ of all diamonds examined.

Many articles published over the last 20 years in the scientific and gemological literature have looked at specific properties of colored diamonds, quality grading characteristics, or particular treatments. Few

See end of article for About the Authors and Acknowledgments.

Gems \& Gemologr, Vol. 54, No. 1, pp. 2-27,

http://dx.doi.org/10.5741/GEMS.54.1.2

(C) 2018 Gemological Institute of America researchers, however, have had the opportunity to examine large quantities of similarly colored natural diamonds and report on their distinctive characteristics. Colored diamonds are extremely rare and, consequently, highly valued. This value factor means that laboratory reports are requested for most colored dia-

\section{In Brief}

- Among natural-color diamonds, those that have a pure green hue are rare and often highly valued.

- While many green diamonds owe their color to natural radiation exposure, three other color causes are often observed.

- These four categories of green diamonds exhibit some distinctive gemological properties and spectral features.

- Separation of some natural- and treated-color green diamonds continues to present a challenge for gemtesting laboratories.

monds prior to being sold. As the creator of the diamond color grading system and the largest provider of these grading reports, GIA is uniquely positioned to examine more colored diamonds than anyone else in the world. 


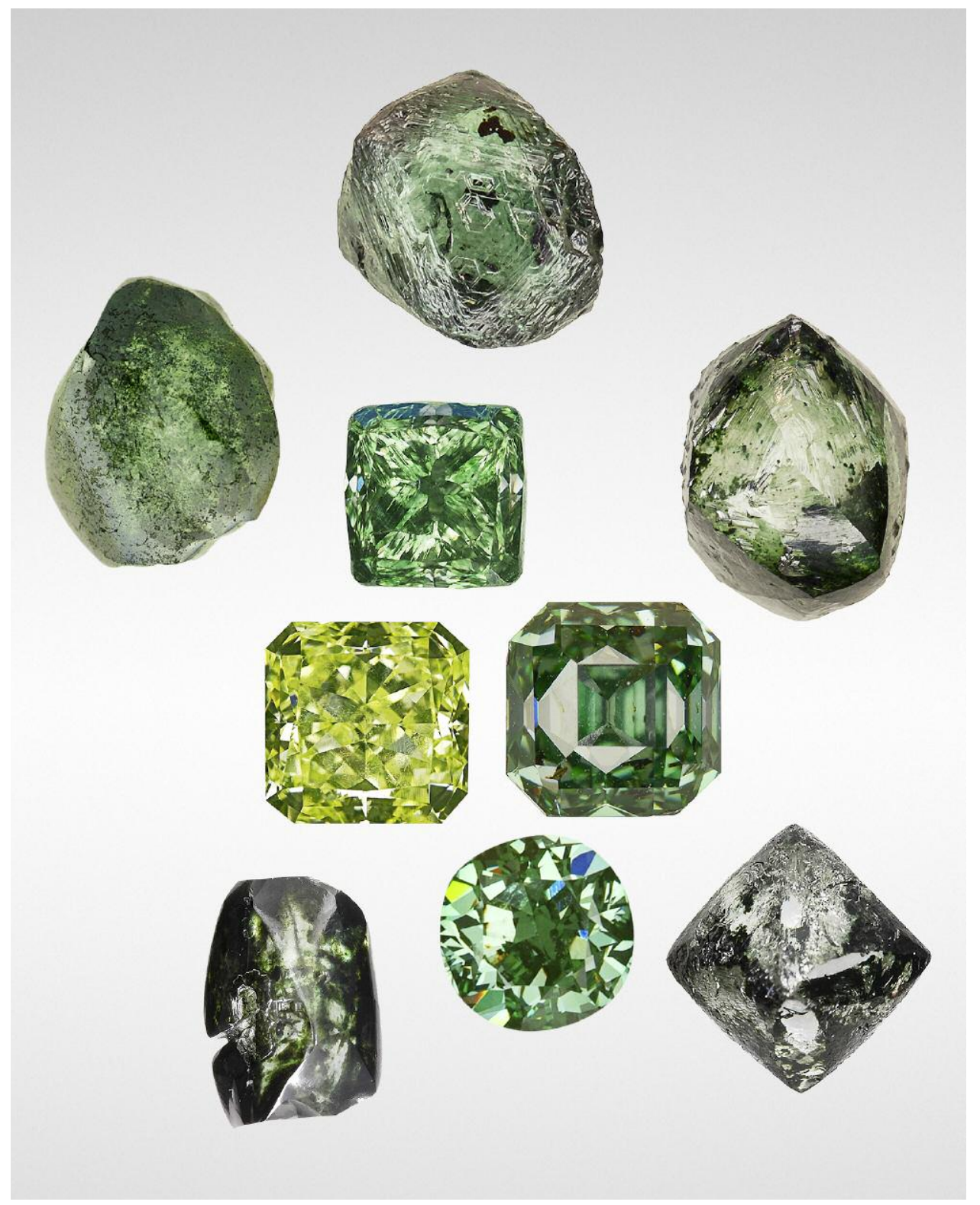

Figure 1. Natural-color green diamonds such as these rough $(0.85-$ $1.07 \mathrm{ct}$ ) and faceted (0.68-1.66 ct) stones submitted to GIA by clients or for scientific study are extremely rare and generally found in South America or Africa. Photos by various GIA staff.

Over the last ten years, scientists at GIA have examined more than half a million natural, fancy-color diamonds and systematically documented their gemological and spectroscopic properties. Through a series of articles, we will discuss the major hue groups of natural-color diamonds in detail that has never before been revealed from such a large sampling of stones. The series will include gemological observations, spectroscopy, and statistical compilations from colored diamonds examined over the last decade at GIA. For more information on data collection methods, please see supplemental table 1 at https://www.gia.edu/gems-gemology/spring-2018natural-color-green-diamonds-beautiful-conundrum.
This first article looks at green diamonds, a beautiful yet enigmatic hue (figure 1). During the last decade, GIA has examined well over 50,000 naturalcolor diamonds with a green hue component, including more than 9,000 with a pure green hue. While there are a few different causes of green color, the most common cause-accounting for nearly half of the natural green diamonds submitted to GIA-is exposure to radioactive minerals and fluids in the earth's crust. Over thousands to millions of years, radiation produced by the decay of isotopes of elements such as uranium and thorium (present in minerals or dissolved in geological fluids) physically damages the diamond structure by removing carbon atoms to cre- 
TABLE 1. Categories of green diamond.

\begin{tabular}{|c|c|c|c|c|}
\hline Cause of green color & Defect responsible & Most common colors & Geological formation & Key gemological observations \\
\hline Radiation damage & GR1 & Green to blue-green & $\begin{array}{l}\text { Exposure to radiation } \\
\text { (minerals or fluids) }\end{array}$ & $\begin{array}{l}\text { Green and/or brown spots or } \\
\text { stains in fractures; color zones }\end{array}$ \\
\hline Green luminescence & $\mathrm{H} 3$ & $\begin{array}{l}\text { Green to } \\
\text { yellow-green }\end{array}$ & Natural annealing & $\begin{array}{l}\text { Localized or dispersed green } \\
\text { fluorescence with focused lighting }\end{array}$ \\
\hline H-related absorption & Unknown H-related & $\begin{array}{l}\text { Gray-green to } \\
\text { brownish green }\end{array}$ & Crystallization in mantle & $\begin{array}{c}\text { Fine particulate clouds, often } \\
\text { patterned }\end{array}$ \\
\hline Ni-related absorption & Unknown Ni-related & $\begin{array}{l}\text { Yellow-green to } \\
\text { green-yellow }\end{array}$ & Crystallization in mantle & No distinctive features \\
\hline
\end{tabular}

ate vacant atomic positions (Meyer et al., 1965; Vance and Milledge, 1972; Mendelssohn et al., 1979; Raal and Robinson, 1981; Titkov et al., 1995; Nasdala et al., 2013). These vacancies (sometimes in combination with other defects) cause the diamond to absorb the blue and red parts of incident visible light, allowing primarily green light to be seen when one observes the stone. This natural irradiation process, however, is easily replicated in a laboratory with electrons, neutrons, or gamma rays, and many green diamonds in the trade have been the product of artificial irradiation treatments (where the radiation exposure times are rapid and controllable) since the late 1940s (Ehrmann, 1950).

The similarity of the natural and laboratory irradiation processes has made it very difficult in many cases for gemologists and laboratories to separate natural- and treated-color green diamonds. Indeed, there have been fewer publications about green diamonds than any other color. The purpose of this article is to provide a detailed account of the gemological and spectroscopic characteristics of natural green diamonds colored by several different mechanisms in order to help the trade better understand these gems.

\section{CAUSE OF COLOR}

Green color in gem diamonds can span a wide range of color descriptions. For the purposes of this article, we include all natural fancy-color diamonds that display a primary green color component under standard grading conditions. In the GIA fancy-color grading system, this includes stones with a pure green color as well as a dominant green color mixed with blue, brown, gray, or yellow. Of the green diamonds seen at GIA over the last decade, most have been yellow-green or pure green, followed by those with gray or brown modifiers and blue components. These different color groupings correlate, to some extent, to four significant atomic-level defect arrange- ments in natural diamond: GR1, H3, hydrogen, and nickel defects (figures 2 and 3). Table 1 summarizes the characteristics of these four groups.

GR1 (General Radiation 1). GR1 defects are empty lattice positions in the diamond structure and serve as the most common mechanism for green color in gem diamonds (Shigley and Fritsch, 1990; Collins, 2001; Shigley and Breeding, 2013). Irradiation, both natural and laboratory-induced, provides sufficient energy to displace carbon atoms from their normal positions in the diamond lattice, leaving vacancies (figure 4; see Koptil and Zinchuk, 2000). The displaced carbon atoms then become what scientists call interstitials: atoms that are out of their normal place and "stuck" between other carbon atoms. GR1 vacancies (figure 2A) cause the diamond to absorb light in the red part of the visible spectrum (zero phonon line ${ }^{1}$, or ZPL, at $\left.741 \mathrm{~nm}\right)$, with associated broad absorption extending from approximately 550 to $750 \mathrm{~nm}$.

Depending on the amount of vacancies and the other impurities and defects present, green diamonds colored by GR1 typically have pure green or blue-green hues (figure 3); irradiation of a light yellow diamond produces a greener color, while irradiation of a colorless diamond causes a bluer color. Most naturally irradiated diamonds have shallow green "skins" or spots on the crystal surface that produce most of the green appearance (Vance and Milledge, 1972; Vance et al., 1973; Kane, 1979b; Fritsch and Shigley, 1991; Roskin, 2000; Eaton-Magaña and Moe, 2016). Upon faceting, these shallow areas of radiation damage are typically removed and the apparently green rough diamond shows little to

${ }^{1}$ See Luo and Breeding (2011) for diagram and description of the zero phonon line. 
A
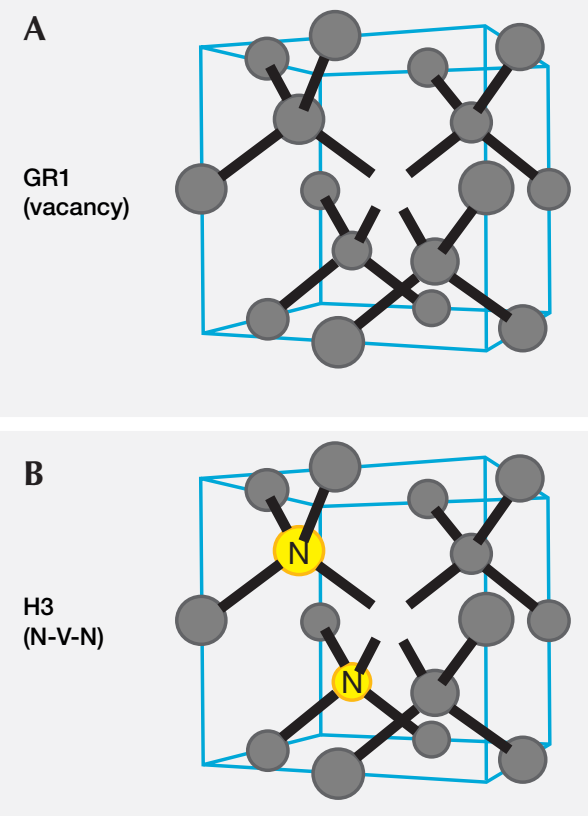

C

H-related defects

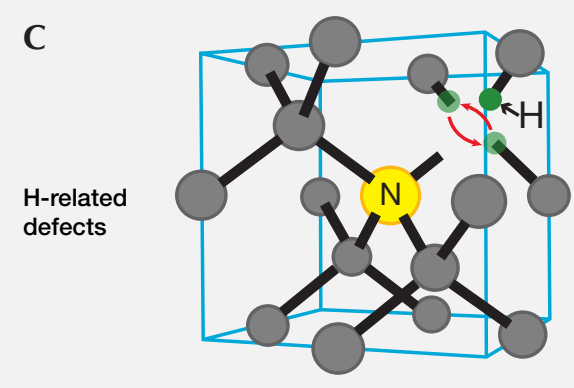

VIS-NIR ABSORPTION SPECTRA
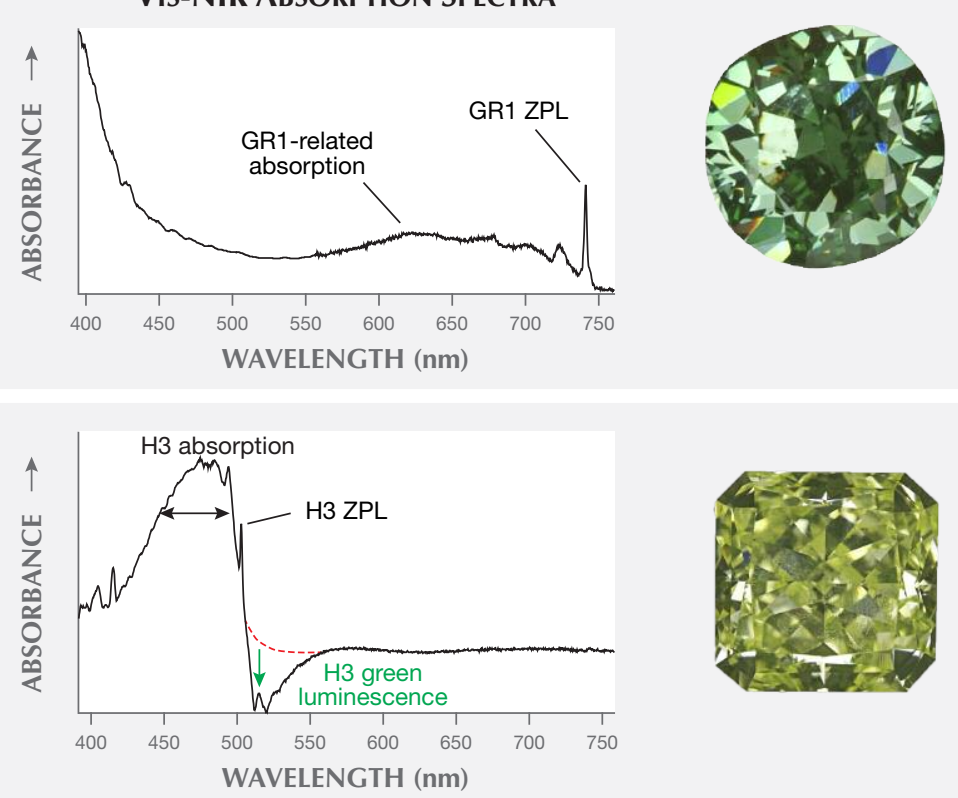
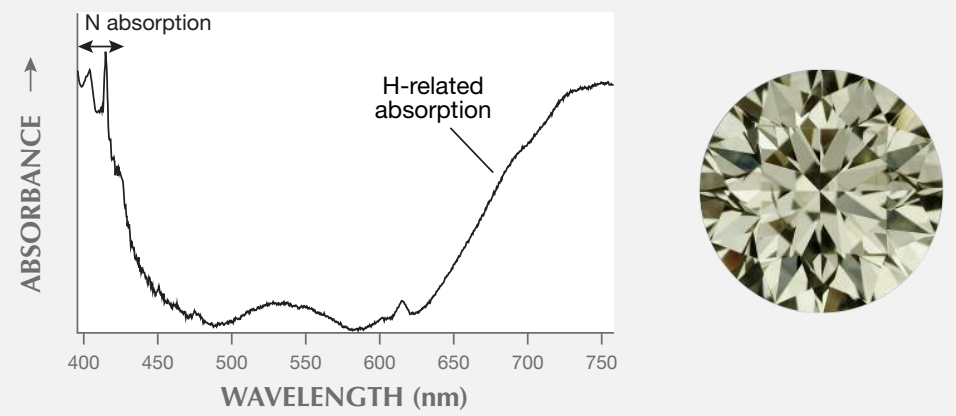

D
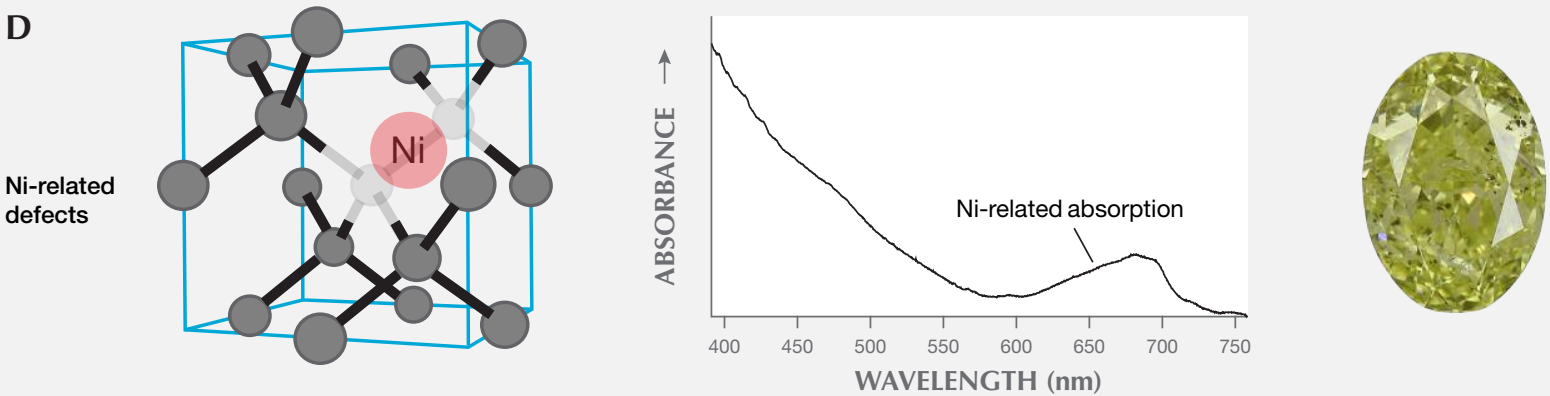

Figure 2. The four main causes of green color in diamond are GR1, H3, H-related, and Ni-related defects. Each absorbs light differently to produce a green color. H3 defects emit green luminescence, seen as the dip in the spectrum below the red dashed line, to cause visible green color.

no color as a finished cut stone (figure 5, bottom row). In some cases, irradiation brings about a deeper green bodycolor that is retained by the diamond after fashioning (figure 5, top row). Vacancies become mobile at temperatures above $600^{\circ} \mathrm{C}$ and start to move around and create new defects in the diamond lattice that can change the stone's color (Collins et al., 2000; Collins, 2001; Eaton-Magaña 


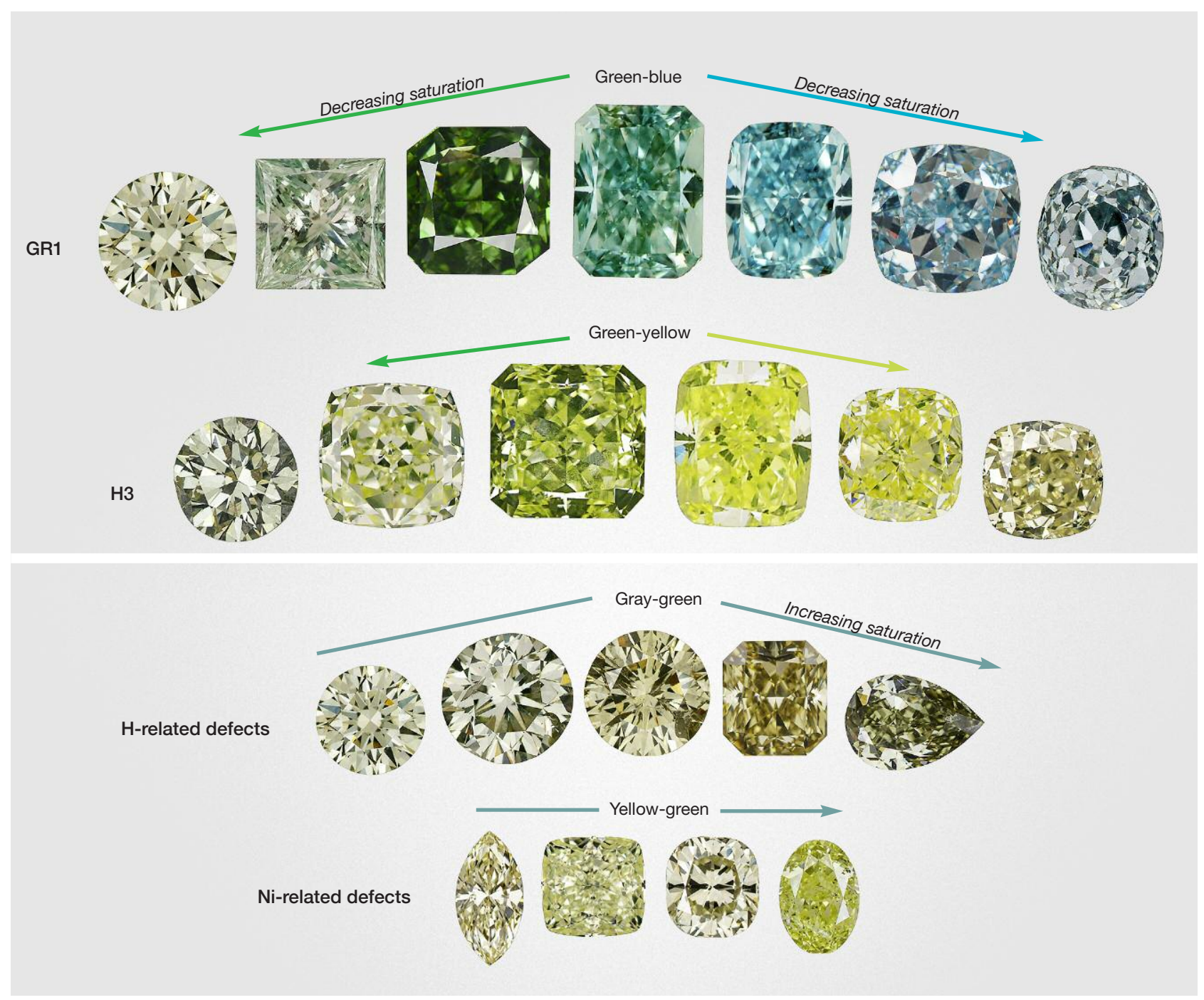

Figure 3. Different causes of color in green diamonds produce slightly different hue ranges, depending on the other impurities and defects present.

and Moe, 2016). During jewelry repair processes, when heating green diamonds colored by this mechanism, jewelers must take great care to avoid destroying the GR1 defects and losing the green color. Heat generated from the friction of polishing can have a similar effect.

The remaining three causes produce less-saturated pure green colors, or green hues with yellow or gray modifiers (figure 3).

Nitrogen-Related Defects: H3. Two nitrogen atoms adjacent to a vacancy in the diamond lattice comprise the $\mathrm{H} 3$ defect, the second most common mechanism for green color in diamond (figure $2 \mathrm{~B}$; see Collins, 2001; Breeding and Shigley, 2009; Shigley and Breeding, 2013). This uncharged defect is usually produced when diamonds containing pairs of nitrogen impurity atoms (A-centers) are exposed to radiation and subsequent heating above $600^{\circ} \mathrm{C}$, either at depth in the earth or in a laboratory (Collins, 2001; Zaitsev, 2003). The vacancies introduced by radiation damage are mobilized during the heating, and they combine with the paired nitrogen impurities to create H3. Unlike GR1, H3 produces green color through emission of light (luminescence), rather than absorption (Collins, 2001; Shigley and Breeding, 2013). H3 absorbs light in the blue part of the visible spectrum (ZPL at $503.2 \mathrm{~nm}$, with associated broad absorption from 420 to $500 \mathrm{~nm}$ ), generating a yellow bodycolor in diamond. When $\mathrm{H} 3$ absorbs visible light, it simultaneously emits green fluorescence. High concentrations of nitrogen in the A form se- 


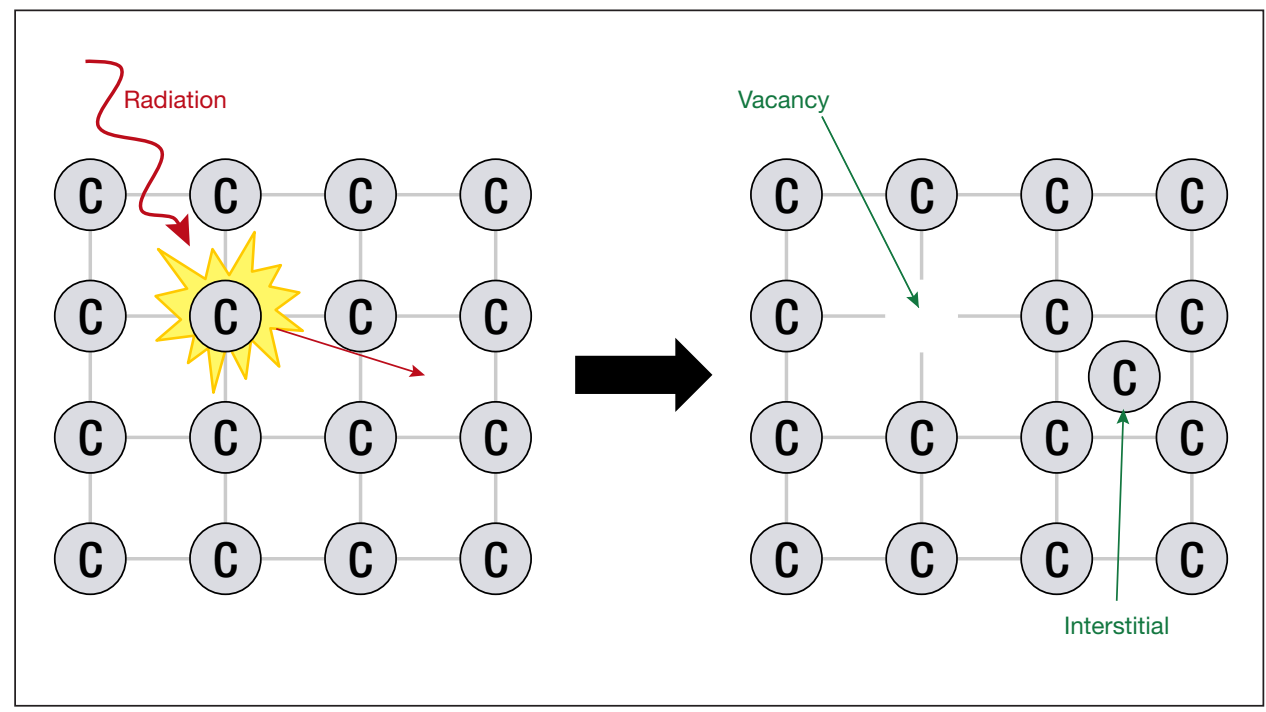

Figure 4. When the carbon atoms that make up the diamond lattice are exposed to high-energy radiation, they can be displaced from their lattice positions to create vacancies. The displaced carbon atoms are called interstitials.

verely quench the $\mathrm{H} 3$ fluorescence (Collins, 2001; Luo and Breeding, 2013), but occasionally a diamond with abundant $\mathrm{H} 3$ defects and a low concentration of nitrogen will emit sufficient fluorescence to bring about a combined yellow-green appearance (figures 2B and 3) (Collins, 2001; Luo and Breeding, 2013). H3 defects are very stable to temperatures exceeding $2000^{\circ} \mathrm{C}$.
Hydrogen-Related Defects. The presence of hydrogen defects in the diamond structure has been known and studied for decades, but very little is known about how $\mathrm{H}$ impurities affect color (figure 2C). The bestknown hydrogen-related defect in natural diamond is the $3107 \mathrm{~cm}^{-1}$ infrared (IR) absorption (Wang and Mayerson, 2002; Goss et al., 2014). This feature is attributed to three nitrogen atoms adjacent to a vacancy

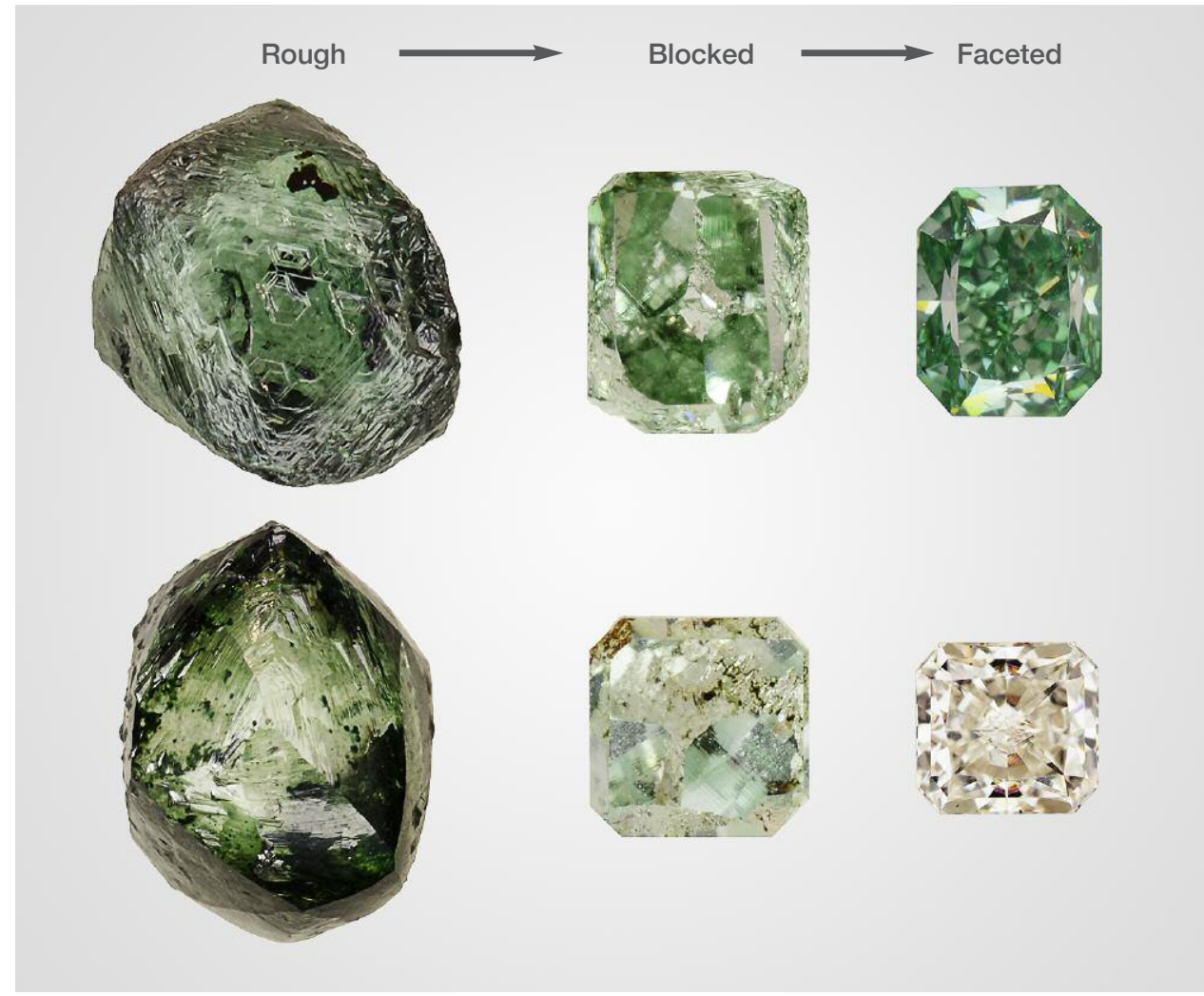

Figure 5. A green diamond's color may be confined to the surface or penetrate deeper into the stone. Upon preforming and faceting, the final product may be green or colorless, depending on the depth of the green coloration. The representative samples shown here are for illustrative purposes and should not be considered a progression of the same stone. 
(N3 defect) that hosts an $\mathrm{H}$ atom (Goss et al., 2014), showing the intimate association of hydrogen and nitrogen impurities in diamond. Several other infrared absorption peaks are thought to be associated with this defect, including those at $1405,2786,3235$, and $4498 \mathrm{~cm}^{-1}$. Unfortunately, the intensity of these IR absorptions does not directly correlate with colorcausing absorptions seen in the visible to near-infrared part of the spectrum. Two primary broad absorption bands spanning the $620-860 \mathrm{~nm}$ range (centered at approximately 730 and $835 \mathrm{~nm}$ ), combined with nitrogen absorption at the blue end of the spectrum, often produce a green color component in H-rich diamonds (figure 2C). The nature of these broad bands is unclear, as they do not occur in all diamonds showing high concentrations of $3107 \mathrm{~cm}^{-1} \mathrm{de}-$ fects, but they also do not occur in diamonds without H-related defects. It is possible that the broad absorptions are related to clouds of hitherto unidentified fine particles (or tiny fluid inclusions) that are relatively common in H-rich diamonds. Green stones colored by H-related defects commonly have brown or gray modifiers (figure 3). While the $3107 \mathrm{~cm}^{-1}$ defect is known to withstand temperatures above $2000^{\circ} \mathrm{C}$ (Goss et al., 2014 and references therein), the stability of the color-producing $\mathrm{H}$-related defects is unknown.

Nickel-Related Defects. Nickel is an uncommon impurity in natural diamonds, considering the large size of the nickel atom that must be accommodated in the tightly packed array of carbon atoms in the diamond lattice. Concentrations of defects related to nickel impurities high enough to produce a green color are less common than other causes, accounting for less than $1 \%$ of all green diamonds seen at GIA over the last decade. Many Ni defects are known from natural and synthetic diamonds (based on observed features in spectra), with the most prominent one in natural diamonds consisting of a complex arrangement of nickel atoms (possibly charged interstitials) and vacancies ( $1.4 \mathrm{eV}$ center; ZPL doublet at 883 and 885 nm; Zaitsev, 2003; Dischler, 2012). Ni defects occur concurrently with nitrogen impurities or other defects in diamond, and the visible absorptions that give rise to green color in these rare stones reflect that pairing. Aggregated N, isolated N, or vacancy-cluster defects may absorb the blue end of the spectrum, and color-affecting $\mathrm{Ni}$ absorption occurs as a broad asymmetrical band from approximately 620 to $710 \mathrm{~nm}$, centered near $690 \mathrm{~nm}$ (figure 2D; see Wang et al., 2007; Ardon, 2013). Typically, the nitrogen-related absorption is stronger than that of $\mathrm{Ni}$, producing an overall yellow-green bodycolor (figure 3). The origin of the color-causing $\mathrm{Ni}$ band is not known, but it is very similar in structure to the absorption sidebands associated with other defects such as N3 and H3. The thermal stability of the broad Nirelated absorption at $685 \mathrm{~nm}$ is not known, but studies of synthetic Ni-bearing diamonds suggest it could be stable to temperatures of $2000^{\circ} \mathrm{C}$ or higher (Zaitsev, 2003).

\section{OCCURRENCE AND FORMATION}

Green diamonds have been reported from both kimberlite-hosted and secondary alluvial sediments in nearly every country that produces diamonds, but some localities consistently produce more of these valuable stones. Green diamonds colored by H3, hydrogen, or nickel defects occur in many localities. For decades the largest producers of green diamonds colored by GR1 defects have been alluvial deposits in Brazil, Guyana, Venezuela, Zimbabwe, the Central African Republic, and India (Draper, 1951; Themelis, 1987; Coenraads et al., 1994; Chaves et al., 1996; Chaves et al., 2001).

The largest and most famous green diamond is the 41 ct Dresden Green (figure 6), sourced from the Golconda mines in India sometime before its earliest historical record in 1722 (Hough, 1913; Rosch, 1957; Bosshart, 1989, 1994; Kane et al., 1990; Astric et al., 1994; Morel, 1994). Several other famous green diamonds have been sold in recent years, including the $5.51 \mathrm{ct}$ blue-green Ocean Dream (mined in the Central African Republic), the 25 ct Gruosi Green (South Africa and never graded by GIA), and the 5.03 ct Aurora Green (Brazil), which sold at auction in 2016 for more than US $\$ 3.3$ million per carat (DeMarco, 2016).

Recent mining in South America has yielded a number of green diamonds from Brazil and Guyana (figure 7). Most show extensive surficial radiation damage with variable amounts of internal GR1-related green coloration. Another recent source is Zimbabwe. Rough diamonds from the Marange region of Zimbabwe (figure 7) are well known to have very dark green or brown coatings of radiation-damaged areas and often show internal green coloration as well (Breeding, 2011). Stones from this source are distinctive in that they also contain high concentrations of hydrogen defects that can enhance the green color from GR1 defects (e.g., a combination of figure 2A and figure $2 \mathrm{C}$ contributes to green color). Production from Zimbabwe has been very high in the last decade, but controversy engulfs these goods, as the 


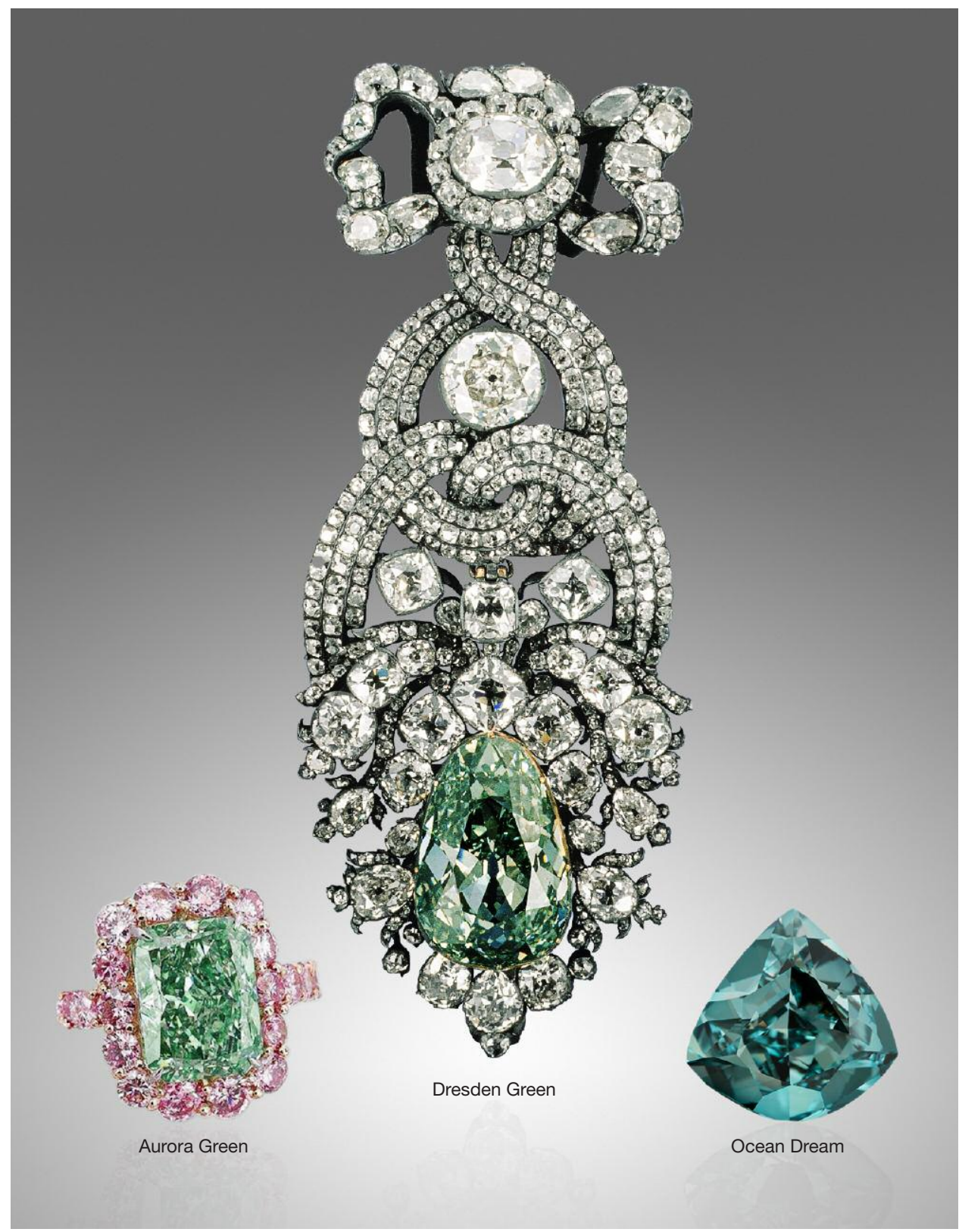

Figure 6. Several famous large diamonds have green color in varying hues. Left to right: the 5.03 ct Aurora Green, the 41 ct Dresden Green, and the $5.51 \mathrm{ct}$ Ocean Dream. The Aurora Green photo is courtesy of Christie's. The Dresden Green photo is by Shane F. McClure, and the Ocean Dream photo is by Jian Xin (Jae) Liao.

United States and other countries still have an embargo on the import of Zimbabwe diamonds due to human rights concerns (Miller, 2011).

The formation mechanism for green diamonds in the earth varies significantly depending on the defects responsible for the color. Stones colored by hydrogen- or nickel-related defects incorporate these impurities, along with nitrogen, when they crystallize in the earth's mantle. Long residence times at high temperatures and pressures contribute to the final arrangement of the complex defects that produce green color in these diamonds, but their inherent color centers are imparted at "birth." Diamonds colored by $\mathrm{H} 3$ defects have a somewhat more complex history. Nitrogen impurities, incorporated during crystal growth, aggregate into A-centers over millions to billions of years at elevated temperatures deep in the earth. Vacancies associated with H3 defects are most commonly created by plastic deformation as the diamonds are violently transported via erupting kimberlite magmas to shallower depths in the earth. The H3 defects are then created by mobilization of the vacancies to combine with A-centers as the diamonds reside at elevated temperatures. In most scenarios, the color centers in H3-based green diamonds form during magma transport (Fisher, 

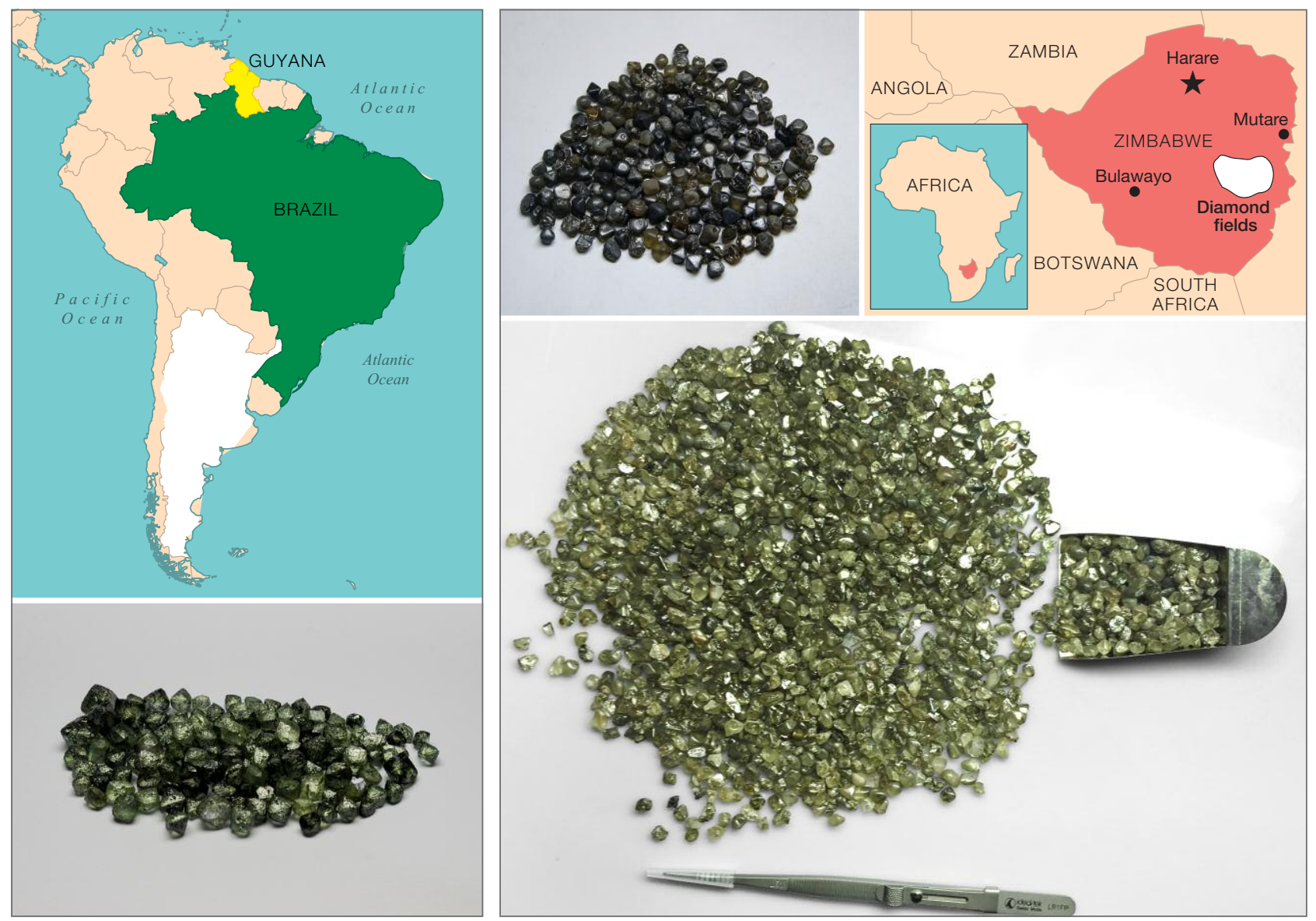

Figure 7. Modern production of green diamonds has come from mines in Guyana and Brazil (left) as well as Zimbabwe (right). The dark brown to greenish "skins" seen on the surfaces of the rough diamonds are due to radiation damage.

2009). The final, and largest, category of green diamonds - those colored by GR1 defects-are generally thought to obtain their color due to late-stage interactions with radioactive minerals or fluids in the earth's crust over thousands to millions of years. Areas of radiation damage in these diamonds range from green to brownish spots caused by direct contact with radioactive minerals (most likely uraninite) to zones of green- to brown-colored "skin" on the surface or within surface-reaching fractures caused by radioactive fluids (figure 8 ; see Vance and Milledge, 1972; Vance et al., 1973; Mendelssohn et al., 1979). The shallow nature (approximately $20 \mu \mathrm{m}$ thick) of the green spots and zones indicates that the radiation damage is primarily caused by alpha particles (see box A for radiation types and sources), most likely from uranium decay (Vance et al., 1973; Nasdala et al., 2013). These spots have been experimen- tally shown to rapidly turn from green to brown at temperatures of $550-600^{\circ} \mathrm{C}$ (Nasdala et al., 2013; Eaton-Magaña and Moe, 2016), indicating that diamonds with green radiation damage must have resided at depths less than about $24 \mathrm{~km}$ (assuming average geothermal gradient of $25^{\circ} \mathrm{C} / \mathrm{km}$ ).

Some green diamonds, however, show color zones that penetrate much deeper than $20 \mu \mathrm{m}$, sometimes even throughout the stones. In these cases, it is likely that some form of beta particle decay (or possibly gamma radiation) is contributing to the irradiation (box A). Some beta decay occurs as part of the same $\mathrm{U}-\mathrm{Th}-\mathrm{Pb}$ decay chain that is likely responsible for the stain-producing alpha damage described above. The overall doses of beta particles possible from these later parts of the decay chain are unknown and the subject of ongoing research. Another viable source for beta decay in the earth's crust with a half-life on 
the order of millions of years appears to be potassium $\left({ }^{40} \mathrm{~K}\right)$, but its natural abundance is very low (box A), leaving the complete story of radiation-related green color zoning unclear-in part because so few diamonds with green bodycolor have been available for scientific study.

\section{GEMOLOGICAL OBSERVATIONS}

Green diamonds have many interesting natural features that can be observed using a gemological microscope. These properties are quite variable, however, depending on the nature of the green color. In this section, we will review the major observations on green diamonds colored by each group of defects. Keep in mind that it is not uncommon for color to be affected by more than one of these color causes simultaneously. For example, many hydrogen-rich diamonds from Zimbabwe also show signs of radiation damage.
Primarily Colored by GR1. The most distinctive and important gemological features of green diamonds colored by radiation damage are surficial radiation spots or coatings (commonly referred to as "stains" if localized and "skin" if generally distributed) and internal color zonation (figure 9, A-E). Radiation stains occur as either green or brown patches of color on the surface of a rough diamond or within fractures. The radiation damage initially has a forest green color (often very dark green, depending on the dosage of the exposure) and then turns olive green at temperatures between 500 and $600^{\circ} \mathrm{C}$ and a reddish brown to dark brown at higher temperatures (Vance et al., 1973; Nasdala et al., 2013; Eaton-Magaña and Moe, 2016). Some experiments have shown that the brown stains disappear at temperatures above $1400^{\circ} \mathrm{C}$ (Eaton-Magaña and Moe, 2016). Radiation stains are thought to be a product of alpha particle bombardment, and structural damage increases to-

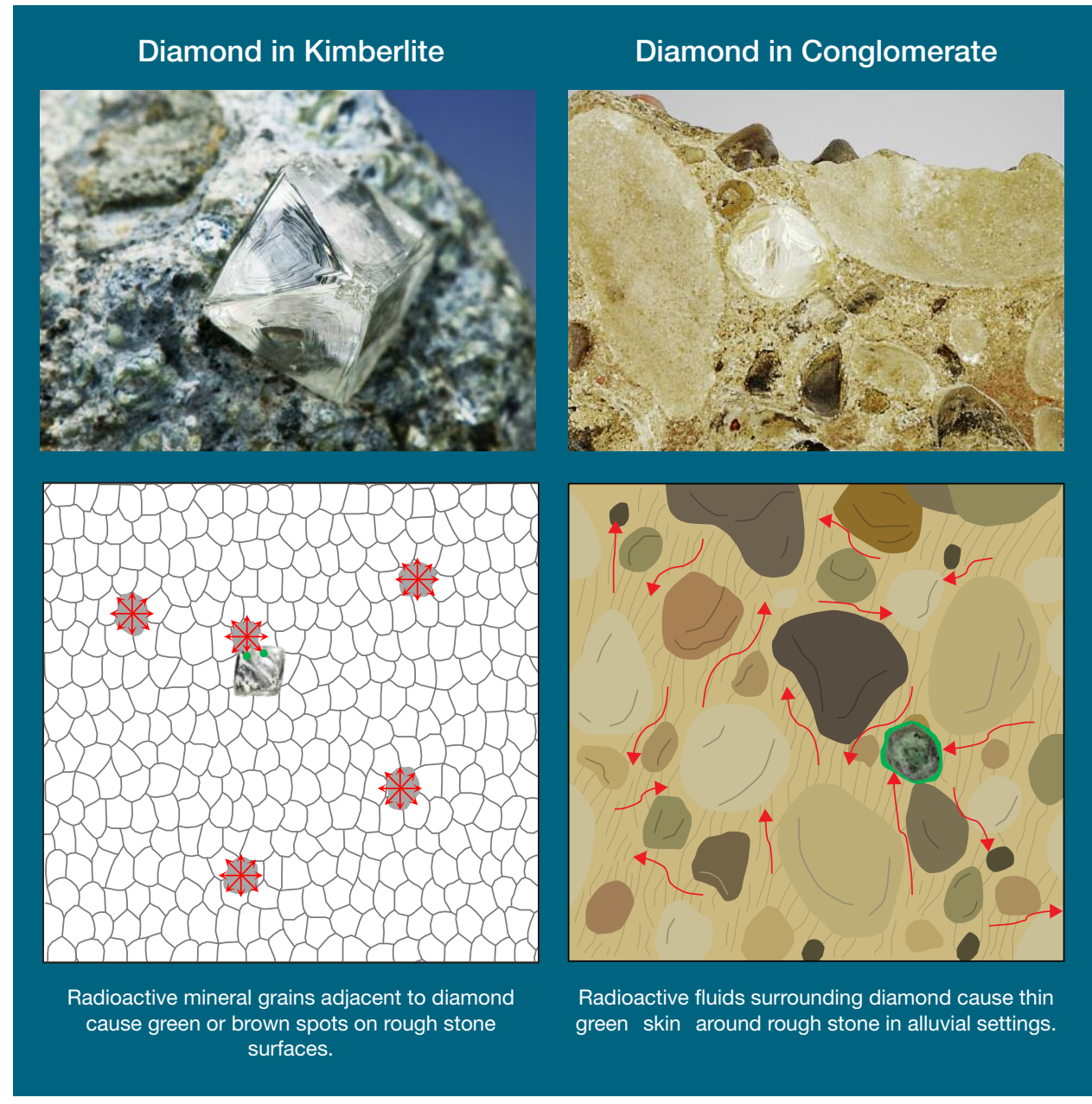

Figure 8. In the earth, diamonds may be exposed to radiation emitted from tiny radioactive mineral grains adjacent to the stones or through interaction with radioactive fluids. The radiation produces either isolated circular radiation "stains" (often from adjacent minerals in the kimberlite host rock, left) or radioactive fluids (usually in alluvial environments) that surround a stone and penetrate into fractures. Photo on the top left courtesy of William F. Larson. Photo on the top right by Robison McMurtry. 


\section{Box A: Summary of Radioactive Decay}

Radioactivity primarily occurs by three mechanisms: alpha decay, beta decay, and gamma emission (figure A1 , top left). Alpha decay involves the expulsion of an alpha particle (two protons and two neutrons-equivalent to a helium atom nucleus) as the parent isotope decays to the daughter. Alpha particles are relatively large and slow, causing them to have low penetration depths (stopped by a sheet of paper, skin, or even air; figure A-1, top right). In natural-color green diamonds, alpha particles produce very thin green spots or skins on the stone's surface due to their shallow penetration depth. Beta decay involves ejection of a beta particle (an electron) as parent converts to daughter. Beta particles are small, high-energy, and high-speed, with moderate penetration depths (stopped by a sheet of aluminum). This type of radiation produces internal color zones in diamond at varying depths and is the most common type of radiation used for diamond treatment. In gamma emission, a parent isotope in an excited nuclear state decays to a daughter isotope by release of gamma rays. These extremely small forms of electromagnetic radiation are the fastest, highest-energy, and most penetrative radioactive decay product. They can fully penetrate a large gem diamond to impart uniform coloration and require a sheet of lead to stop their progress.
As shown in figure A-1 (bottom), the most likely sources of alpha decay in the earth are the radioactive isotopes of uranium $\left({ }^{238} \mathrm{U}\right.$ and $\left.{ }^{235} \mathrm{U}\right)$ and thorium $\left({ }^{232} \mathrm{Th}\right)$. Radiogenic thorium is three times more abundant than uranium in the earth's crust, but its decay is very slow, with a half-life (the time it takes for half of the parent isotope to decay to the daughter) of 14 billion years. ${ }^{238} \mathrm{U}$ is the most abundant radiogenic uranium isotope and has a half-life of 4.5 billion years, making it a more feasible source of radiation damage for diamond. Most uranium is found in the minerals uraninite and zircon. The best sources of beta decay to create green bodycolor in diamond include late-stage radiogenic decay within the uraniumlead decay chain and potassium. ${ }^{40} \mathrm{~K}$, the only significant radiogenic isotope of potassium, has a similar abundance in the earth's crust and a much shorter half-life of 1.3 billion years (figure A-1, bottom). ${ }^{40} \mathrm{~K}$ is hosted in common crustal minerals such as micas and feldspars. Because these radioactive isotopes are extremely scarce in the earth's mantle, most green diamonds are thought to obtain their color from radiation exposure in alluvial deposits, where crustal minerals are more abundant, rather than in their kimberlite host rocks. In addition, the elevated temperatures of the mantle cause vacancies in the diamond lattice to be extremely mobile, and thus unstable.

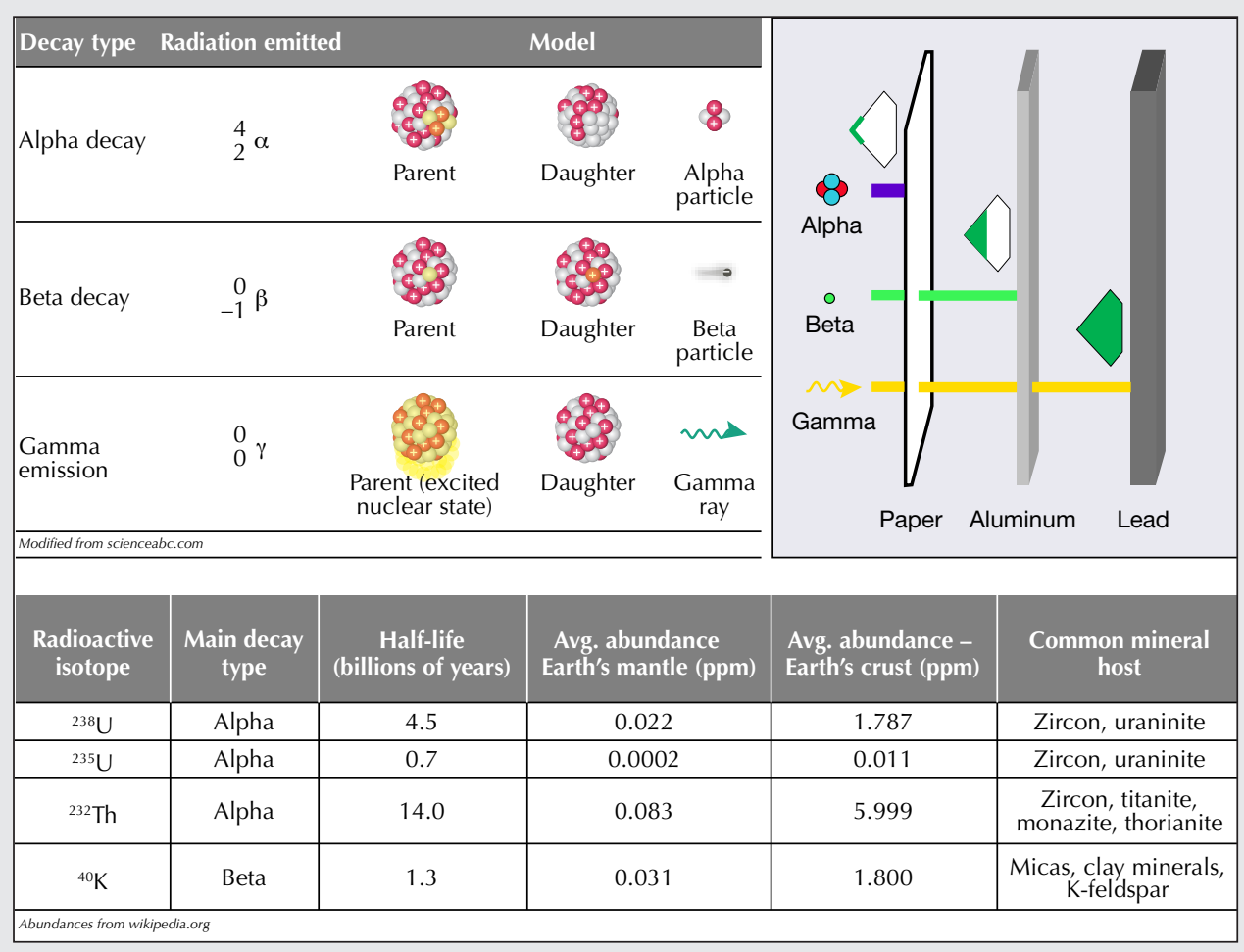

Figure A-1. Radioactive decay usually involves emission of alpha or beta particles or gamma rays. Each type of radiation has a different penetration depth in diamond, with alpha particles only affecting the surface and gamma rays penetrating throughout. Isotopes of uranium, thorium, and potassium are the most likely to affect diamonds in natural settings. These isotopes vary in abundance in the earth. 

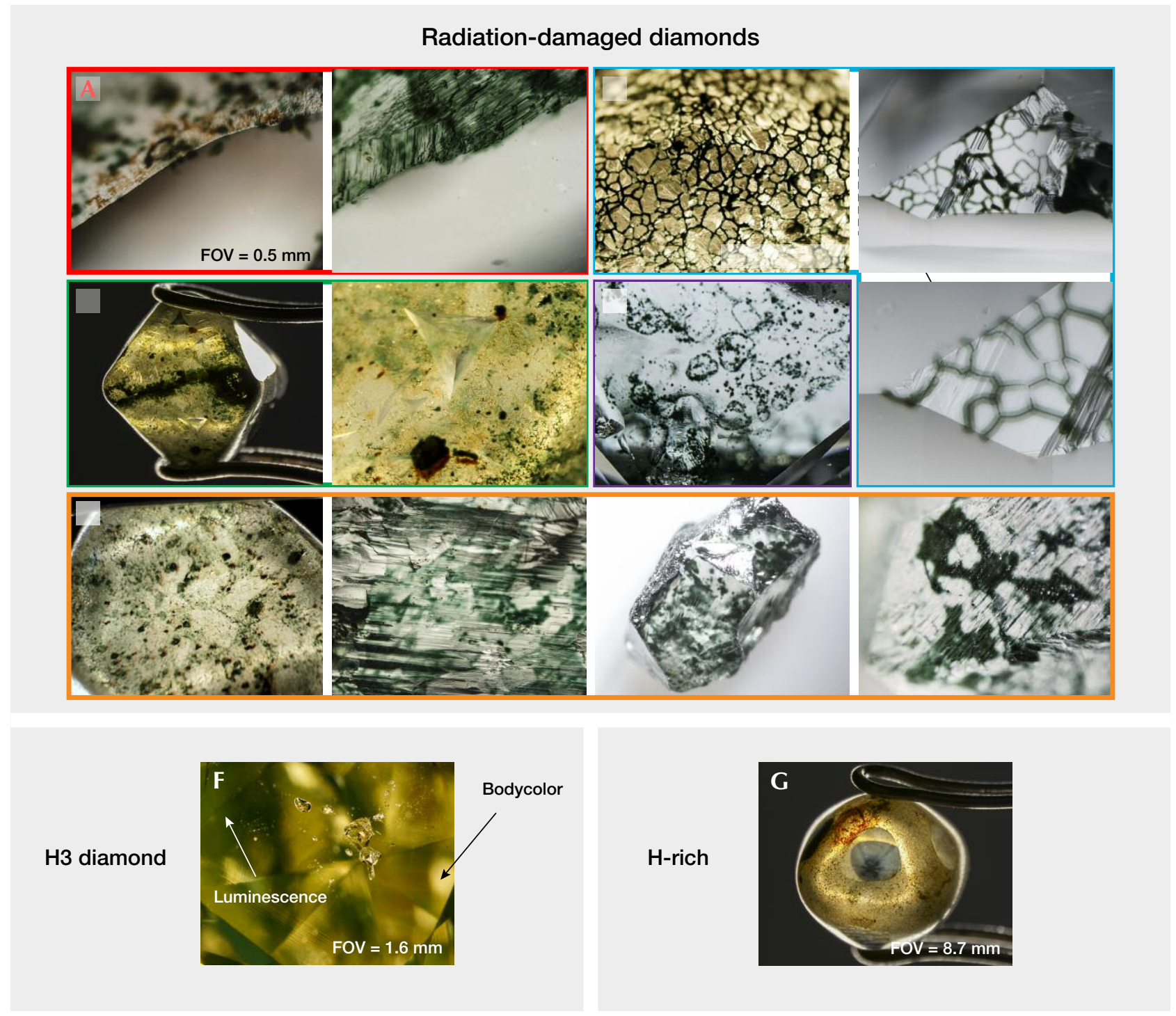

Figure 9. Radiation stains in diamond (A-E) occur initially as green spots that may turn brown with exposure to heat above $500^{\circ} \mathrm{C}$ (Vance et al., 1973; Nasdala et al., 2013; Eaton-Magaña and Moe, 2016). The stains are caused by alpha decay and occur as spots or thin coatings on the surface ( $A, C$, and E). Green color usually penetrates only a few micrometers deep (A). Natural indentations or fractures allow radioactive fluids to penetrate and leave stains within the features (B). Occasionally, radioactive fluids between grain boundaries of adjacent minerals preserve their positions as green spotted patterns (D). H3-colored green diamonds (F) usually show yellow bodycolor with green luminescence. H-rich diamonds often have distinctively patterned clouds of microinclusions (G). Photomicrographs by various GIA staff.

ward the center of the area. While the stains can occur in any shape or size, depending on the diamond's surface exposure to radioactive material, most take the form of circular spots that likely represent halos extending from multiple point sources (figures 8 and 9A, 9C, and 9E). Damage to the atomic lattice by alpha particles causes a slight volume expansion in the diamond and an elevated surface at the locus of the stain (Nasdala et al., 2013). The green or brown color penetrates to depths of usually not much more than $20 \mu \mathrm{m}(0.02 \mathrm{~mm})$, creating a shallow zone of green color adjacent to the stain(s) (figure 9, A-B; Nasdala et al., 2013; Eaton-Magaña and Moe, 2016).

When many stains are concentrated together, a rough diamond may be covered with large patches of 

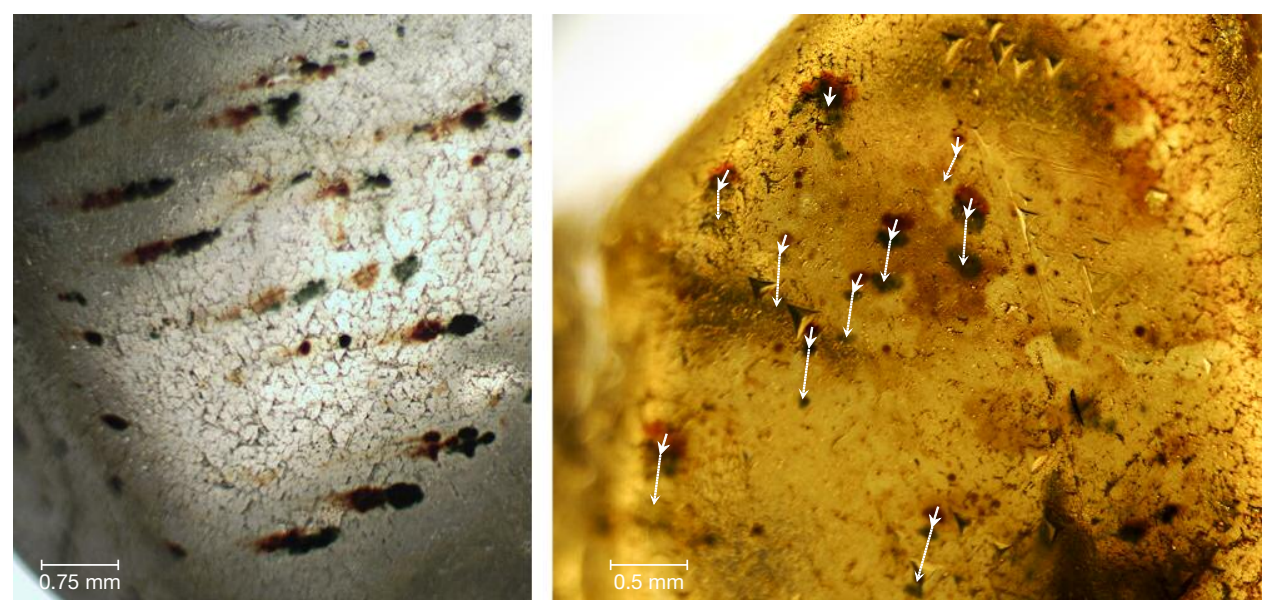

Figure 10. The occurrence of brown and green spots of the same size and shape, but shifted in position, strongly suggests multiple stages of radiation exposure, heating, and movement of the diamond relative to the adjacent radioactive minerals producing alpha particles that cause the damage. Photomicrographs by C.M. Breeding.

green zones. Similarly, very thin skins of relatively uniform green color may coat the surfaces and fractures (figure 9, $\mathrm{C}$ and $\mathrm{E}$ ). These more pervasive areas of radiation damage probably represent radioactive fluids (rather than point sources of particles of radioactive minerals) surrounding a diamond and penetrating into the fractures and crevices (figures 8 and 9B). Patterns of green staining often mimic grain boundaries of minerals that would have surrounded the diamond, suggesting that radioactive fluids were also present between mineral grains in some ancient alluvial environments (figure 9D; see also Mennell, 1915; Guo et al., 1986). Green color zones that extend deeper must be related to beta or gamma radiation (or possibly neutron bombardment). While these zones do occur in some natural diamonds, they are much less common and therefore must represent some unusual radiation exposure conditions. For example, the color of the 41 ct Dresden Green was described by Kane et al. (1990) as "evenly distributed throughout the gem," despite its large size $(29.75 \times$ $19.88 \times 10.29 \mathrm{~mm})$. This may represent a diffused green color that penetrated uniformly because the diamond was surrounded by radioactive fluids.

Sometimes a complex history of residency in the earth can be gleaned from radiation stain patterns. A number of examples have been observed where green and brown radiation spots with identical shapes are offset from each other in one direction, sometimes with three or more instances of the same radiation spot along the same trajectory (figure 10). Due to the dynamics of how the spots change color with temperature, we know that the farthest brown spot was oldest and that the stone subsequently moved one or more times due to some tectonic or compaction process while the radiation source remained present. Heating episodes exceeding $500^{\circ} \mathrm{C}$ must have accom- panied the shifting process to cause the spot color changes, followed by a cooling and subsequent re-irradiation of a new spot (Vance et al., 1973). The change in diamond position relative to its environment, combined with the unchanged spot shape, suggests that these spots were adjacent to radioactive mineral grains rather than fluid pockets.

Colored by H3. As mentioned earlier, H3 defects primarily cause yellow bodycolor in diamond, with the green component caused by a strong undertone from a luminescence reaction to visible light. Using a fiber-optic or other strongly focused light source, green luminescence (sometimes referred to as "transmission") with a watery appearance is usually seen in green diamonds colored by $\mathrm{H} 3$ defects (figure 9F; see also Kane, 1979a). Although the green color may be uniform in the stone, the structure of $\mathrm{H} 3$ as a combination of A-centers with vacancies means that if nitrogen aggregate pairs and vacancies are irregularly distributed, the luminescence will show a similar pattern. For example, diamonds with grain lines caused by plastic deformation sometimes have higher concentrations of A-centers along the graining (Massi et al., 2005) and higher amounts of vacancies available (Fisher, 2009). Consequently, fluorescence from $\mathrm{H} 3$ defects in these diamonds can often be seen as an alternating banded pattern between green and nonfluorescent regions.

H-Related Green Color. Unlike the two previous groups, direct evidence of the defects related to green color in H-rich diamonds is typically not visible with a microscope. Some features, however, do occur primarily in diamonds with a high concentration of hydrogen defects. The most common features of these stones are milky particulate clouds that have sharp, 
angular boundaries with relatively non-included regions. Sometimes these clouds outline a six-rayed star pattern that is well known in hydrogen-rich stones (figure 9G; see also Wang and Mayerson, 2002; Rondeau et al., 2004). When viewed under UV light, $\mathrm{H}$-rich diamonds often fluoresce yellow as well.

Ni-Related Green Color. Gemological observations from Ni-rich green diamonds are generally not distinctive. Some have been reported to show a uniform weak green luminescence to visible light, similar to that from $\mathrm{H} 3$, but it has not been directly linked to the Ni impurities.

\section{LABORATORY GRADING}

Stones weighing up to $2.0 \mathrm{ct}$ comprised $82 \%$ of GIA's intake of natural green diamonds, with those between 1.0 and 2.0 ct accounting for nearly $40 \%$ of that amount (figure 11). Rounds were most prevalent (36\%), followed by cushions $(26 \%)$, cut-cornered rectangles $(12 \%)$, and pears $(9 \%)$ (figure 11$)$. Color grade distribution, as mentioned earlier, included $54 \%$ yellow-green, $28 \%$ pure green, and $12 \%$ blue-green, with the remainder having gray or brown undertones (figure 12). Many green diamonds are colored by a combination of defects, making it difficult to assign specific percentages to each cause of color. As an estimate, we used a random sample of 250 natural green diamonds colored by the four main defects to determine that $34 \%$ were colored by GR1, $21 \%$ by $\mathrm{H} 3,16 \%$ by hydrogen defects, and $1 \%$ by nickel defects, while the remainder included some combination of these color centers (figure 12). No discernible trends were observed from clarity grades.

\section{ABSORPTION SPECTROSCOPY}

Absorption spectroscopy measurements are nondestructive and provide a detailed look at a diamond's atomic structure by passing light of different wavelengths through the stone and measuring what wavelengths (energies) are absorbed by the impurities and defects present. IR absorption gives information about the impurities in the diamond lattice, while ultraviolet-visible (UV-Vis) absorption reveals the color-producing defects. Each group of green color defects has unique spectroscopic features.

IR Absorption. Details of the major impurity present (nitrogen or boron), as well as the configuration of the atoms of those impurities relative to the rest of the carbon lattice in diamond (diamond type), are quickly and directly measured from IR spectroscopy. In addition, information about other impurities such as hydrogen can be inferred through evaluation of IR features created by complex defects involving those atoms. Infrared spectra are typically collected with the stone kept at room temperature conditions (Anderson, 1943a, 1943b, 1943c; Collins, 2001; Zaitsev 2003).

Figure 11. Most of the natural green diamonds submitted to GIA during the last decade have weighed 1-2 ct or less. Fewer than 5\% are larger than 4 carats. Rounds were the predominant shape, followed by cushion, cut-cornered rectangle, and pear shapes.
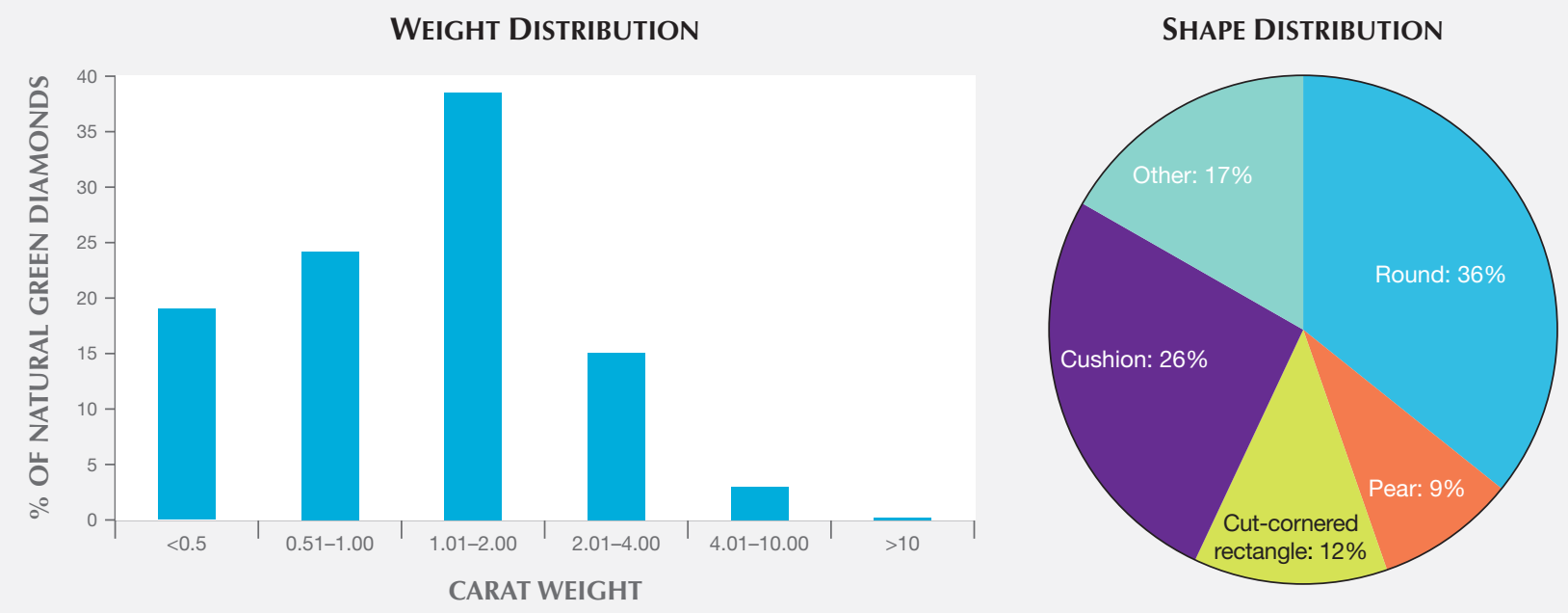

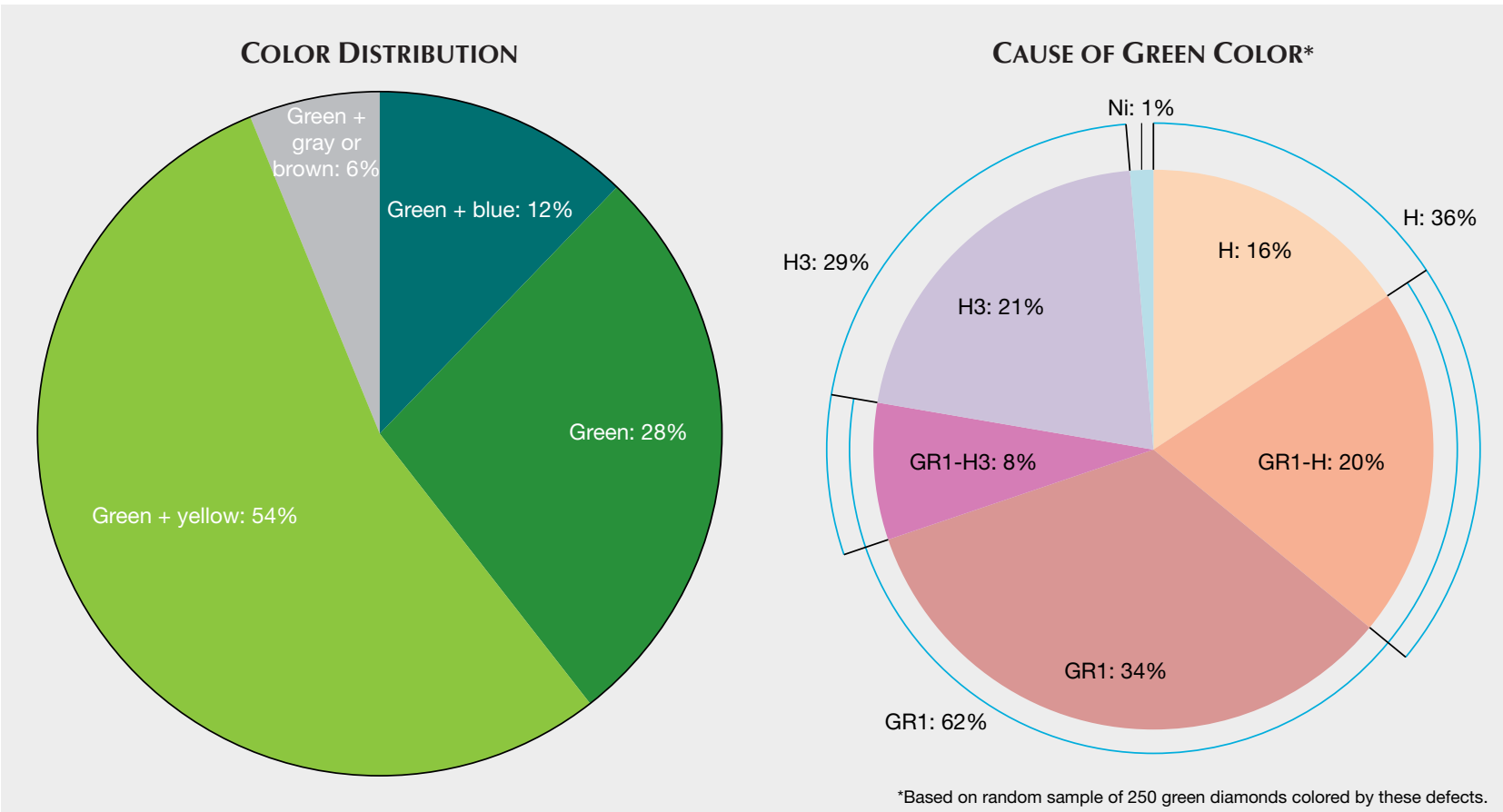

Figure 12. Natural green diamonds submitted to GIA labs over the last decade have been dominated by green + yellow and pure green hues, followed by green + blue color combinations and stones with grayish or brownish undertones. The cause of green color was largely GR1, followed by $\mathrm{H3}, \mathrm{H}$, and Ni, with many stones showing combinations of these defects.

Green diamonds colored by $\mathrm{H} 3, \mathrm{H}$, and Ni defects are all type Ia (containing $\mathrm{N}$ impurities). Those with significant $\mathrm{H} 3$ defects usually contain low to moderate concentrations of nitrogen, typically both as Acenters (pairs) and B-centers $(4 \mathrm{~N}+\mathrm{V})$ along with associated platelet defects (figure 13; see also Woods, 1986 for platelet defect description). Higher-nitrogen diamonds tend to show very little to no green color from $\mathrm{H} 3$ luminescence, even when $\mathrm{H} 3$ concentrations are high, because the high levels of A-centers tend to quench the green fluorescence, leaving only the yellow bodycolor due to absorption of $\mathrm{H} 3$ (Collins, 2001; Luo and Breeding, 2013). Low concentrations of H-related defects seen at 4496,3107, and $1405 \mathrm{~cm}^{-1}$ are not uncommon. Green diamonds that owe their color to $\mathrm{H}$-related defects have very high concentrations of both H-related defects $(4496,4167,3236,3107,2812$, 2785 , and $1405 \mathrm{~cm}^{-1}$ ) and $\mathrm{N}$ impurities in the form of A- and B-centers, as well as platelets $\left(1360-1370 \mathrm{~cm}^{-}\right.$ $\left.{ }^{1}\right)$ and related peaks at approximately $1435,1498,1525$, and $1549 \mathrm{~cm}^{-1}$ that shift depending on the A/B center ratio. The concentrations of aggregated $\mathrm{N}$ impurities in these stones are so high as to saturate most IR spectrometer detectors (i.e., the peaks extend beyond the upper edge of the infrared spectrum). Green stones col- ored primarily by Ni-related defects contain very low amounts of nitrogen impurities, predominantly as Acenters (with only occasional traces of B-centers). In many cases, IR spectra also reveal traces of C-centers (i.e., single, substitutional nitrogen) as well as a series of peaks including $3137,3143,3180,3187,3202,3242$, 3257 , and $3272 \mathrm{~cm}^{-1}$ that are ascribed to $\mathrm{H}+\mathrm{C}$-center defects. Relatively low but variable amounts of the $\mathrm{H}$ related defects seen in $\mathrm{H} 3$ diamonds are also present.

Diamonds colored green by GR1 defects from natural radiation span the gamut from high-nitrogen type Ia stones to type IIa diamonds with no measureable nitrogen impurities (figure 13). Likewise, the $\mathrm{H}$ content varies widely. The reason for this lack of correlation is the secondary nature of the radiation damage. Any diamond can be exposed to radioactive minerals or fluids after its formation to develop GR1 defects and possibly a green color. The preexisting impurities and other defects will determine whether the green stone resulting from radiation damage has a yellow, gray, or brown undertone, but the green color is entirely introduced secondarily from the original condition of the diamond. One radiation-related defect that occurs as a weak peak in the IR spectrum of some intensely green type Ia natural diamonds is 


\section{IR ABSORPTION SPECTRA}
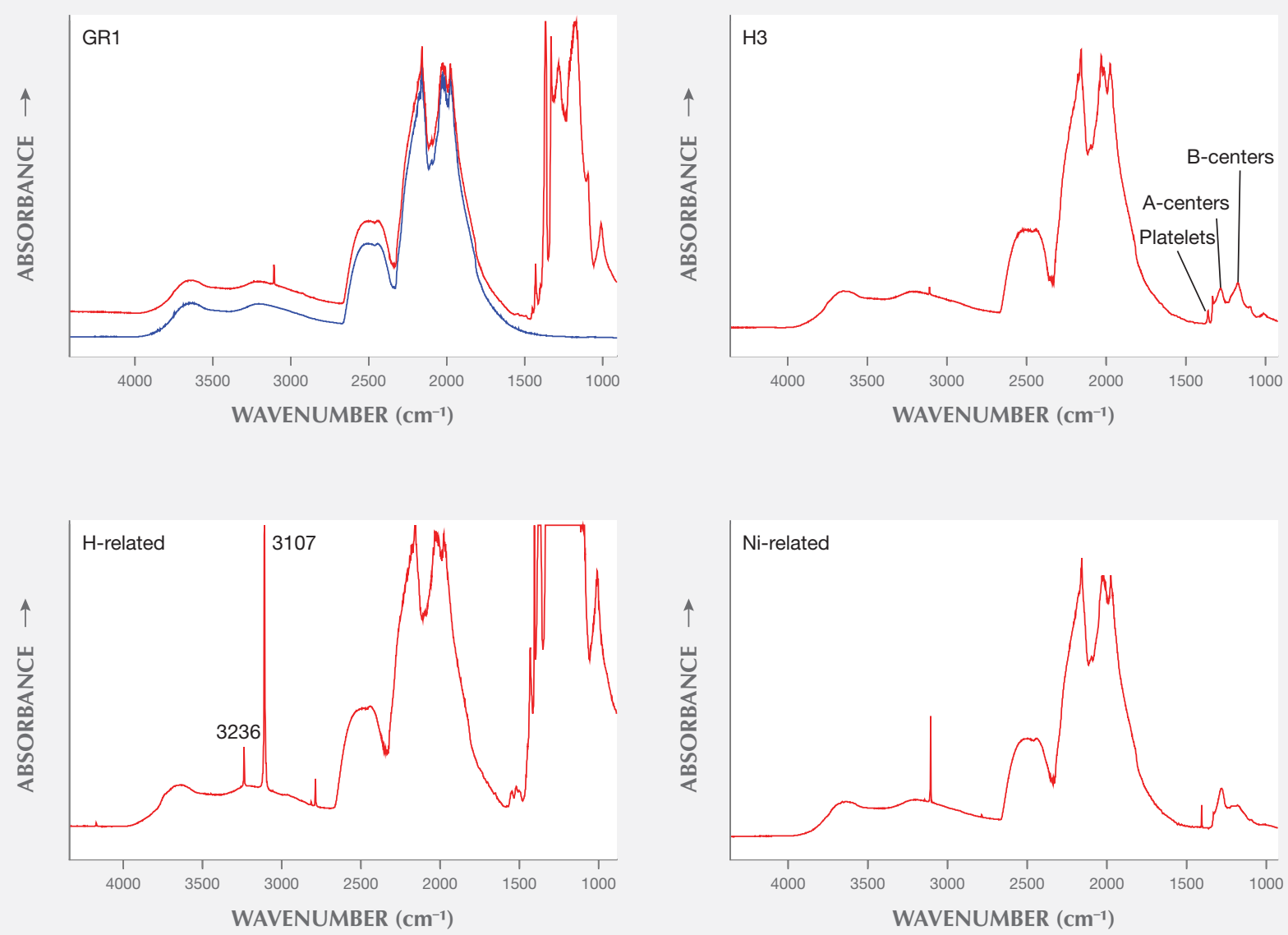

Figure 13. IR absorption spectra from three of the four groups of green diamond defects show generally consistent patterns of nitrogen concentration and aggregation (type Ia). Due to the post-growth nature of radiation damage, GR1-colored diamonds (upper left) tend to span the entire range from type IIa (blue line) to high-nitrogen type Ia stones (red line).

$\mathrm{H1a}$, an interstitial nitrogen defect at $1450 \mathrm{~cm}^{-1}$ (Zaitsev, 2003; Dischler, 2012).

UV-Vis-NIR Absorption. Ultraviolet/visible/near-infrared spectroscopy measures the color center absorptions that produce the color we see in a diamond. Although most primary impurity absorptions occur in the IR region, many complex defects (and even some very simple ones) absorb light in the visible part of the spectrum to produce color. These spectra are typically collected at liquid nitrogen temperature (approximately $77 \mathrm{~K}$ ) to observe narrow peaks from temperature-sensitive defects (Collins, 2001; Shigley and Breeding, 2013).

In the "Causes of Color" section, we discussed the main visible absorption features responsible for color in green diamonds containing GR1, H3, H-re- lated, and Ni-related defects. Here we will detail the less prominent features that tell us more about the nature of the coloring mechanism and how it relates to the color we see. For diamonds colored by $\mathrm{H} 3$ or $\mathrm{Ni}$ defects alone, UV-Vis-NIR spectra tend to be relatively consistent from stone to stone because both of these defect centers intrinsically coexist with aggregated nitrogen, which always absorbs light toward the blue end of the spectrum and commonly occurs with $\mathrm{N} 3$ defects $(3 \mathrm{~N}+\mathrm{V})$ at $415 \mathrm{~nm}$ (figure 14). The same is generally true of $\mathrm{H}$-rich diamonds, except that these stones often have accompanying absorptions related to $\mathrm{H}$ at $615 \mathrm{~nm}$ and more distinctive "cape" absorptions related to nitrogen at $478 \mathrm{~nm}$ (N2). Additionally, H-rich green diamonds often have a broad band centered at around $530 \mathrm{~nm}$ (figure 14). The combination of this $530 \mathrm{~nm}$ band with the N- 


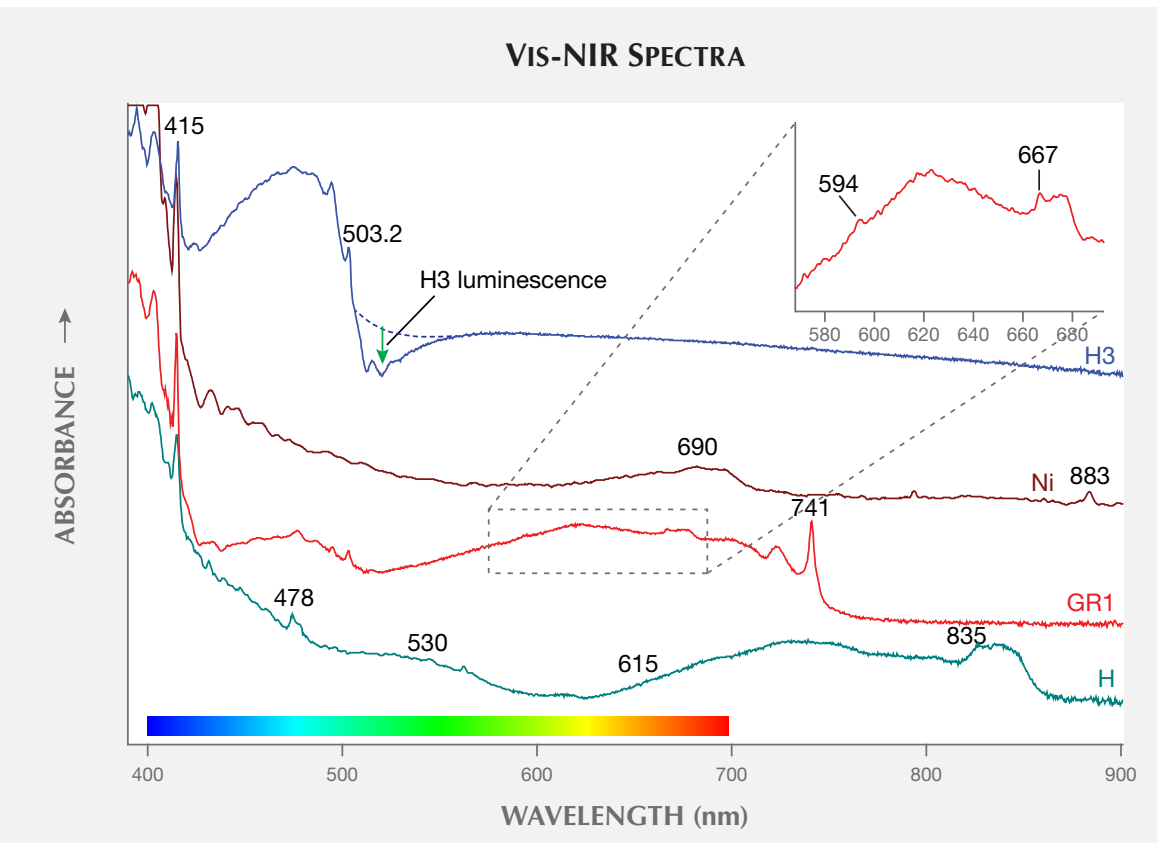

Figure 14. Visible absorption spectra from each of the four green color mechanisms illustrate how different absorptions-and luminescence in the case of H3-can produce green color. In each case, absorption below $450 \mathrm{~nm}$ due to nitrogen is important for green coloration.

and H-related visible absorptions causes the lower absorbance part of the spectrum between 500 and $600 \mathrm{~nm}$ to be elevated, resulting in the gray undertone that is common in $\mathrm{H}$-rich green diamonds.

Radiation damage in diamond produces a number of defect centers in Vis-NIR spectra in addition to the primary GR1 color center (figure 14). The four most common of these defects occur at 496 (H4), 503.5 $(3 \mathrm{H}), 594$, and $667 \mathrm{~nm}$. Natural diamonds remain buried in the near-surface region of the earth for variable amounts of time even after they are exposed to radioactive minerals or fluids. Depending on the depth of residency, green diamonds are commonly exposed to elevated temperatures of a few hundred degrees Celsius that cause a natural annealing effect (Vance et al., 1973). The $667 \mathrm{~nm}, 594 \mathrm{~nm}$, and 3H defects can all occur from radiation damage alone, without annealing, and are often seen in stones with green radiation stains. The $667 \mathrm{~nm}$ center consists of a carbon interstitial that anneals out at $400-500^{\circ} \mathrm{C}$ (Zaitsev, 2003). The $594 \mathrm{~nm}$ center (known to gemologists as the 595 line) is a defect of uncertain structure, possibly consisting of nitrogen atoms and vacancies or interstitials (Collins, 1999; Zaitsev, 2003). It anneals out at approximately $1000^{\circ} \mathrm{C}$. The $3 \mathrm{H}$ defect is a split carbon interstitial that increases in intensity with annealing and remains stable to at least $600^{\circ} \mathrm{C}$ (Zaitsev, 2003). The H4 defect at $496 \mathrm{~nm}$ is more complex, consisting of four $\mathrm{N}$ atoms and two vacancies, and generally forms with radiation dam- age and subsequent annealing to temperatures above $600^{\circ} \mathrm{C}$. H4 is very stable and withstands temperatures of at least $1400^{\circ} \mathrm{C}$ (Collins, 1997; Zaitsev, 2003).

It is important to remember that radiation damage can also occur simultaneously with any of the other defects that cause green color. It is not uncommon to see H-rich or $\mathrm{H} 3$ diamonds with GR1 defects (figure 12, right). We have even observed the occasional Ni-rich diamond with GR1. The combination of multiple causes of green color can dramatically intensify the overall green appearance but often makes identification more difficult, as we will discuss later.

\section{LUMINESCENCE SPECTROSCOPY AND IMAGING}

Luminescence spectroscopy measures the light emitted by a diamond in response to stimulation by another source of light, such as a laser or UV lamp. Photoluminescence (PL) uses lasers of different wavelengths to produce emission spectra that reveal the defects present in a stone. DiamondView imaging exposes diamonds to very high-energy UV light $\mid<230$ $\mathrm{nm}$ ) to stimulate fluorescence that can be imaged with great detail (Welbourn et al., 1996). Both techniques are nondestructive and provide important information about the structure of natural green diamonds.

PL Spectroscopy. PL analysis is one of the most useful and sensitive techniques for defect characterization in diamond. Defects occurring at concentrations 


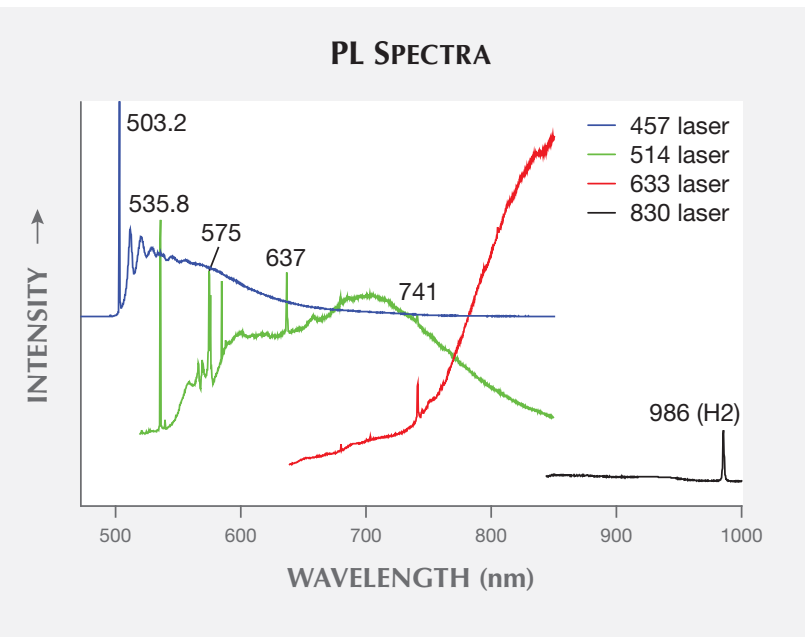

Figure 15. PL spectra of H3-colored green diamonds reveal that $H 3, H 2$, and $N V$ defects and a $535.8 \mathrm{~nm}$ peak are the main features. Intrinsic diamond Raman lines have been removed for clarity.

as low as the ppb (parts per billion) level can easily be detected (Breeding et al., 2010; Eaton-Magaña and Breeding, 2016). Like UV-Vis-NIR absorption, PL measurements of green diamonds are usually focused in the visible range of the electromagnetic spectrum and need to be collected at low temperatures (around $77 \mathrm{~K}$ ) to resolve many spectral peaks. There are hundreds of PL peaks that might occur in diamond, and some are activated only by certain laser excitation wavelengths since each laser excites luminescence features from diamond in a particular limited range of wavelengths. It would be impossible to characterize every feature-and little is known about many of them-so we have chosen to report representative PL features that are associated with each group of green diamonds.

Green diamonds colored by $\mathrm{H} 3$ defects show relatively few prominent PL features. The main peaks are $\mathrm{H} 3(503.2), 535.8,575\left(\mathrm{NV}^{0}\right), 637\left(\mathrm{NV}^{-}\right), 741(\mathrm{GR} 1)$, and $986 \mathrm{~nm}(\mathrm{H} 2)$ (figure 15). $\mathrm{H} 2$ has the same structure as $\mathrm{H} 3(\mathrm{~N}-\mathrm{V}-\mathrm{N})$ but carries a negative electrical charge. Negatively charged defects indicate the presence of trace amounts of single substitutional nitrogen impurities serving as electron donors (Collins et al., 2000; Collins, 2001). The nature of the $535.8 \mathrm{~nm}$ feature is unknown, and PL-detectable trace amounts of GR1 are common in many natural diamonds. $\mathrm{H}$ rich green diamonds also contain very few notable PL features. Peaks at 694, 700, 716, 787, and 793 nm are usually encountered with occasional $\mathrm{H} 3$ defects (503.2 $\mathrm{nm}$; figure 16). Interestingly, most of these defects $(694,700,787$, and $793 \mathrm{~nm}$ ) have previously

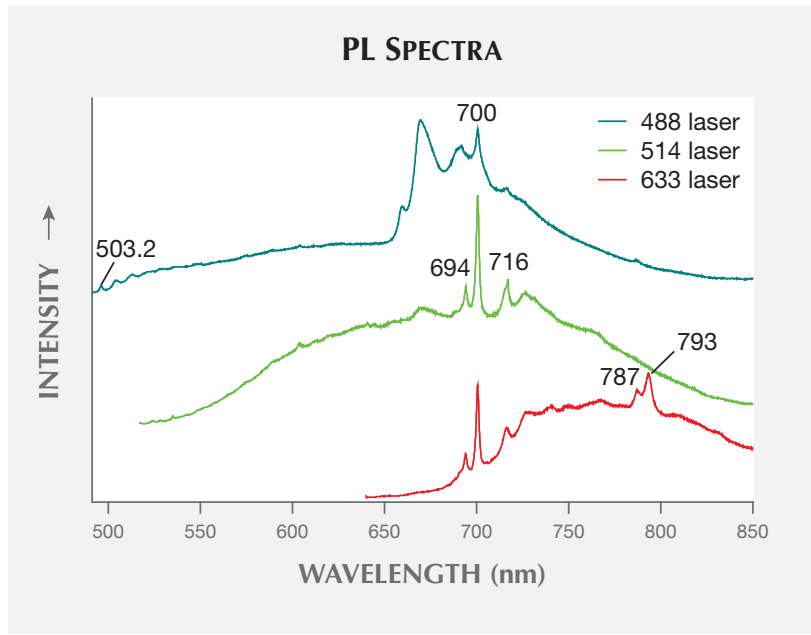

Figure 16. PL spectra from $H$-rich green diamonds mainly show features attributed to Ni and possibly H). No features were observed with $830 \mathrm{~nm}$ laser excitation (not shown). Intrinsic diamond Raman lines have been removed for clarity.

been assigned to complex Ni-N defects (Bokii et al., 1986; Zaitsev, 2003). From our observations, at least two of them, 700 and $793 \mathrm{~nm}$, correlate with A-aggregate concentrations in high- $\mathrm{H}$ diamonds. It is possible that these $\mathrm{H}$-rich stones are also high in $\mathrm{Ni}$ content but, due to natural annealing and trapping of the $\mathrm{Ni}$ impurities by more-abundant aggregated nitrogen, no longer show the $883 / 885 \mathrm{~nm}$ Ni defect. If so, they represent a more $\mathrm{N}$-rich, mature form of Nirelated green diamond. $\mathrm{Ni}$-colored green diamonds show many of the same PL features, including the 700,787 , and $793 \mathrm{~nm}$ peaks discussed above that are attributed to Ni-N complexes. Yet these stones also show many other narrow PL features, among which the most consistent and prominent are 603 and 668 $\mathrm{nm}$ along with the very strong and well-known $\mathrm{Ni}$ doublet at 883/885 $\mathrm{nm}$ described earlier (figure 17; see also Zaitsev, 2003; Wang et al., 2007). Little is known about the $603 \mathrm{~nm}$ PL feature, but the one at $668 \mathrm{~nm}$ has been attributed to a Ni defect (Zaitsev, 2003).

PL spectra collected from diamonds colored by GR1 can vary considerably due to irregular distributions of radiation damage across a stone's surface and interior. PL features related to radiation damage are also dramatically affected by heating, even to relatively low temperatures of a few hundred degrees. In order to represent the PL defects of natural radiation damage, the features below are from Brazilian green diamonds with abundant green radiation stains (meaning they have not been heated to $550-600^{\circ} \mathrm{C}$ ). Similar stones from other localities show the same 


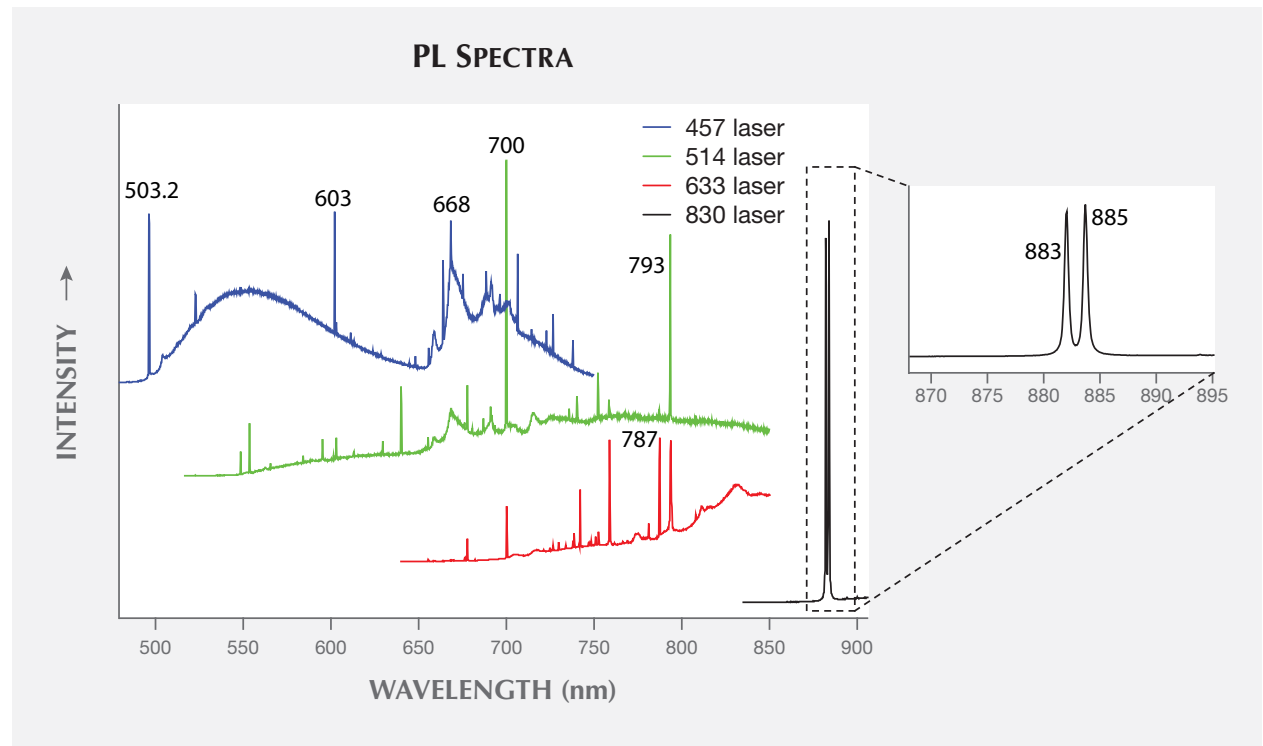

Figure 17. PL spectra from Ni-rich green diamonds contain abundant peaks, including the same Ni-related defects seen in the $H$-rich stones (though they are much stronger here), as well as the 883, $885 \mathrm{~nm}$ Ni-related doublet. Intrinsic diamond Raman lines have been removed for clarity.

features. The strongest PL peaks in these green diamonds are stable defects at 741 and $744 \mathrm{~nm}$ (GR1), $503.2 \mathrm{~nm}(\mathrm{H} 3), 637 \mathrm{~nm}\left(\mathrm{NV}^{-}\right)$, and $986 \mathrm{~nm}(\mathrm{H} 2)$. Weaker, much less stable features at 526, 587.9, 647.2 , and $722.5 \mathrm{~nm}$ are all related to interstitial atoms produced by radiation damage (figure 18). The $526 \mathrm{~nm}$ feature has been assigned as nitrogen bound to carbon interstitials, and the one at $587.9 \mathrm{~nm}$ is thought to be an interstitial nitrogen atom (Zaitsev, 2003). Little has been reported in the literature about the 647.2 and $722.5 \mathrm{~nm}$ defects, but ongoing work by one of the authors (CMB) has shown that these two are related to each other and likely represent interstitial $\mathrm{N}$ atoms. The 647.2 and $722.5 \mathrm{~nm}$ PL features are completely destroyed by heating to $500^{\circ} \mathrm{C}$, and thus do not occur in natural green diamonds with radiation stains that have turned brown.

DiamondView. While photoluminescence records a semi-quantitative spectrum of the light emitted from a diamond at a single spot, DiamondView imaging records the qualitative fluorescence pattern produced

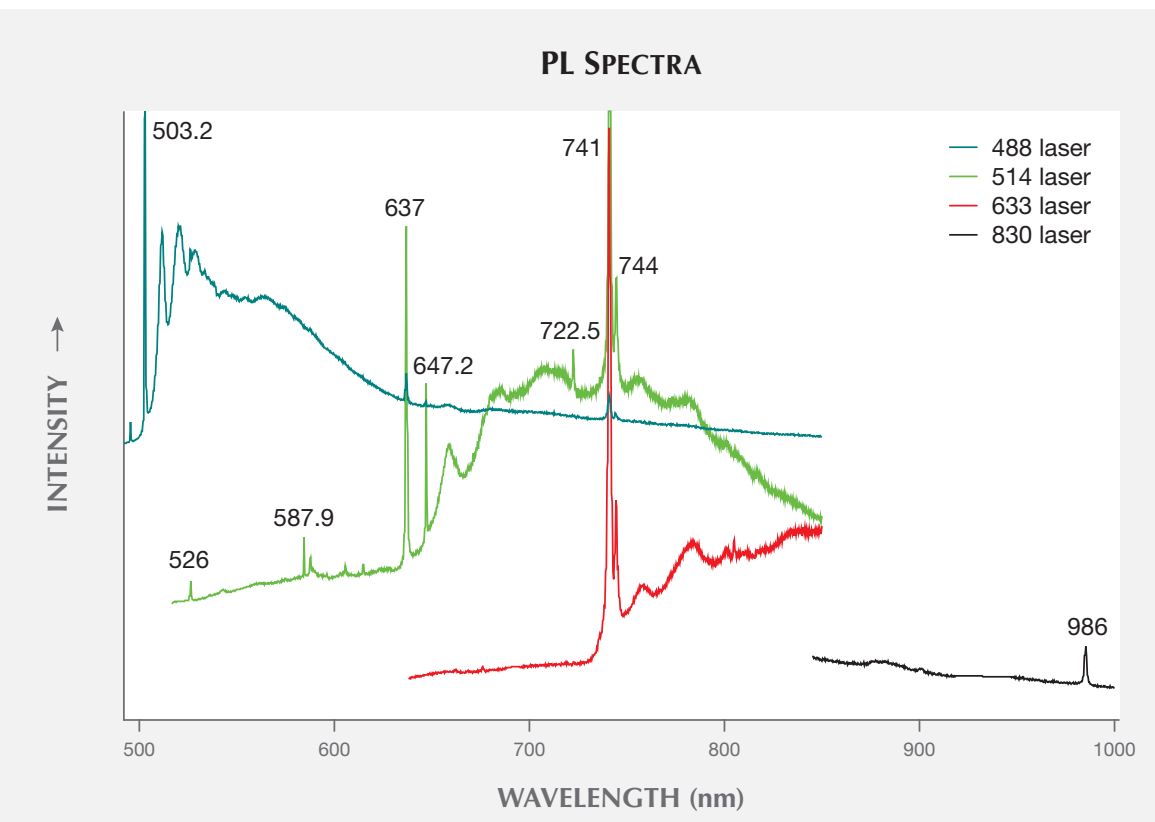

Figure 18. PL spectra from GR1-colored diamonds with green radiation stains reveal relatively stable defects such as GR1, $N V^{-}$, and $H 3$, along with unstable interstitial defects at 526, 647.2, and 722.5 nm. Intrinsic diamond Raman lines have been removed for clarity. 

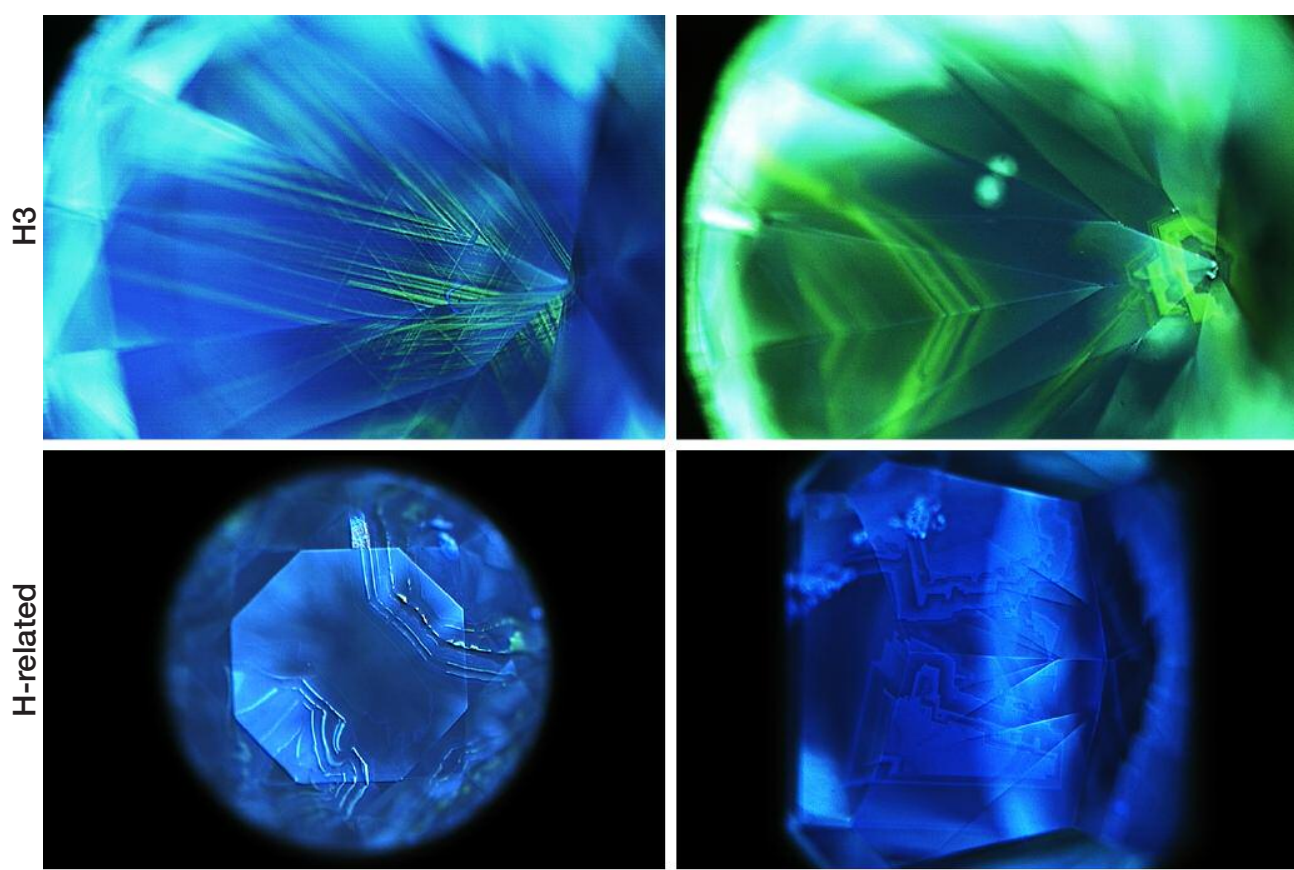

Figure 19. Diamond-

View fluorescence im ages from each group show relatively few differences. H3 diamonds mainly show weak to strong isolated green fluorescence, while
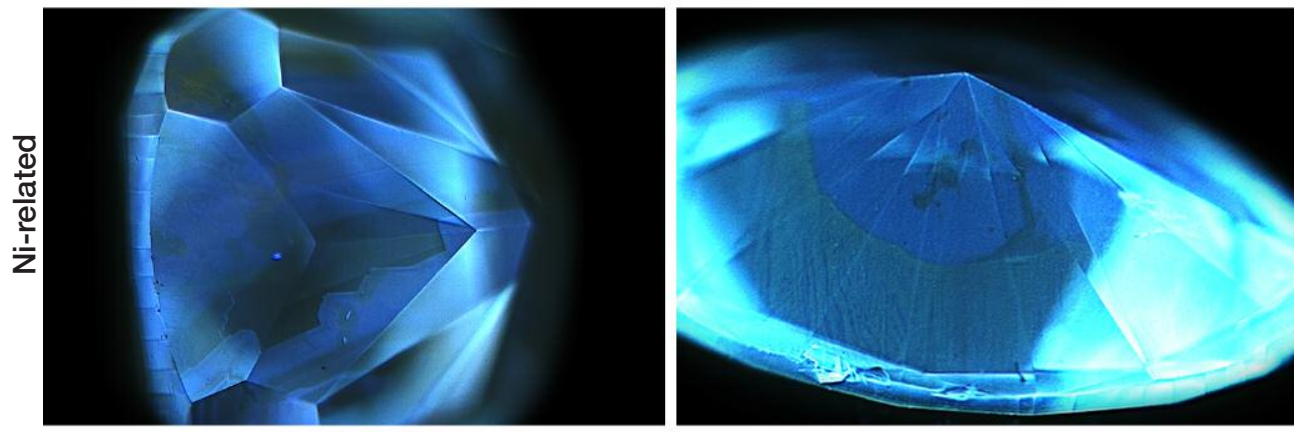
GR1 diamonds with stains display inert areas due to quenching of fluorescence by strong radiation damage. $H$ - and Ni-related diamonds mainly show patterned blue fluorescence.

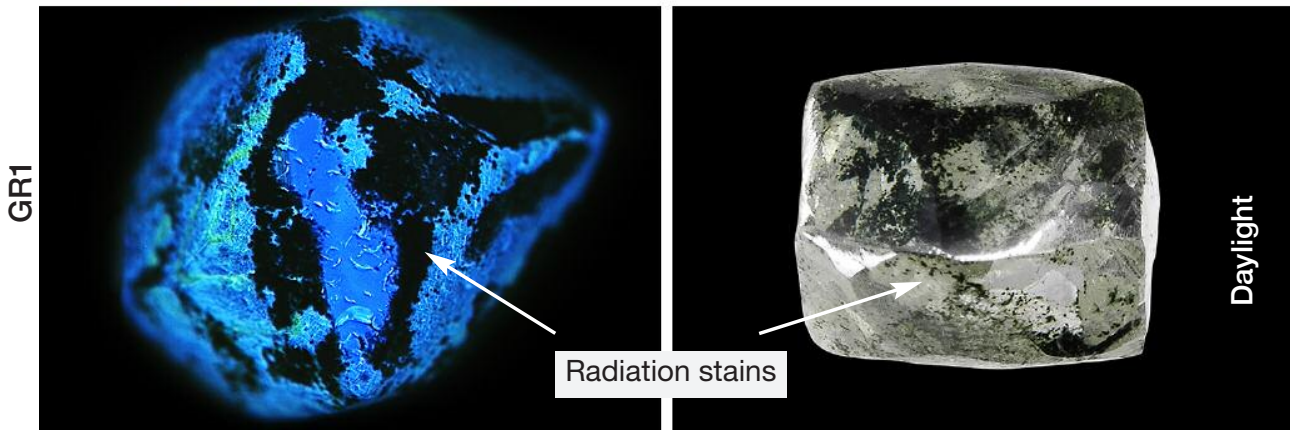

In green diamonds colored by $\mathrm{H} 3$ defects, the over the entire instrument field of view to reveal spatial variations in luminescence. These patterns can be used to separate natural from laboratory-grown diamonds, but also to interpret some of the stone's impurity incorporation and growth history. The DiamondView uses ultra-short-wave UV light $\mid<230$ $\mathrm{nm}$ ) to excite fluorescence from diamonds at room temperature (Welbourn et al., 1996). During UV exposure, the diamond can be rotated to observe fluorescence patterns in several directions. most obvious feature shown in the images is green fluorescence from H3 (figure 19), which often follows particular growth zones or plastic deformation structures. Blue fluorescence from N3 defects is also usually visible. The ratio of green to blue fluorescence in the images directly correlates with the total concentration of $\mathrm{H} 3$ defects. H-rich diamonds typically show weaker overall fluorescence that is almost always blue from N3 defects. Irregular patterns reflect 


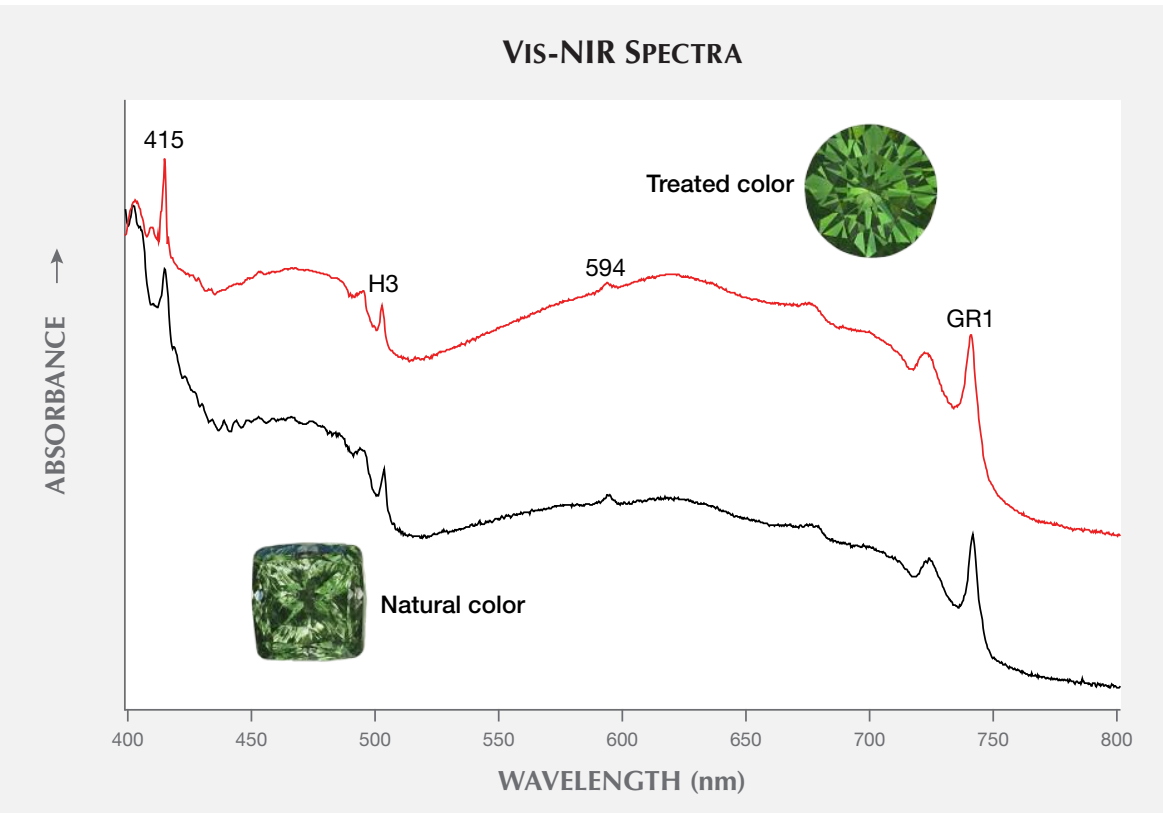

Figure 20. Naturally irradiated and laboratoryirradiated green diamonds show very similar spectra because the same defects are created by both processes. As a result, the color origin of many green diamonds proves very difficult to identify.

cuboid growth, which is often apparent with $\mathrm{H}$ diamonds. Isolated green $\mathrm{H} 3$ luminescence occurs occasionally at the boundaries between growth zones. Ni diamonds usually contain multiple zones of contrasting fluorescence colors. Blue from N3 is almost always present along with inert zones and/or regions that fluoresce yellowish green (figure 19). The green may be from a Ni-related defect, as there are typically few or no H3 defects seen in these stones. The DiamondView images from green diamonds colored by GR1 are extremely variable because they primarily reflect the defects present in the stones prior to natural irradiation. The observations suggest that high levels of radiation damage tend to quench fluorescence, resulting in areas with radiation staining that appear inert in DiamondView images (figure 19).

\section{IDENTIFICATION CONCERNS}

Identification of colored diamonds is a two-step process involving determination of genesis (grown in the earth versus a laboratory) and color origin (a product of natural processes versus treatment). In the case of green diamonds, the first step is relatively easy, but the color origin determination is often problematic. While all the diamonds discussed in this article were identified by GIA as having natural color, green diamonds in general are the single largest group of diamonds that receive "Undetermined" color origin reports from gemological laboratories. Laboratory irradiation using an electron beam takes only a few minutes and can be performed commercially at low cost. This treatment has been performed regularly since the 1950s to create green diamonds, so nearly every green stone in the trade must be regarded with suspicion. Other treatment methods such as embedding diamonds in radioactive compounds, cyclotron and linear accelerators, and gamma ray exposure in nuclear reactors have been employed less frequently to achieve a green color.

As might be expected with the similar processes in nature and the laboratory, the absorption and luminescence spectra from natural- and treated-color green diamonds are virtually identical in many cases (figure 20). Furthermore, almost any kind of diamond can be subjected to irradiation (in nature or the laboratory) to produce a green hue. This means that the preexisting defects, and thus the resulting radiationrelated defects, can vary as much as natural heterogeneity in diamond itself. In the absence of obvious color zoning related to laboratory treatment (green culet and a cyclotron "umbrella" pattern), all green diamonds should be sent to a gemological laboratory.

At GIA, we continue to conduct our own irradiation treatment experiments and to examine known natural-color green diamonds from around the world to refine our identification criteria and reduce the number of "Undetermined" reports issued each year. As with all instances of gem testing, the identification of natural- versus treated-color in diamond is based on a variety of features. These identification 


\section{Box B: ChameleON Diamonds}

Among green diamonds, chameleon diamonds are a fascinating curiosity. They do not directly owe their green color to any of the four major defects discussed in this article. In fact, they span a wide range of color, from predominantly yellow to green hues. What makes these stones particularly interesting is that when heated or left in the dark for an extended period of time (days to weeks), they temporarily lose their green color and change to yellow or orangy hues (figure B-1, top) through energetic shifts in the broad visible absorption bands that cause their color. Within a few seconds to several minutes of being removed from darkness or allowed to cool after heating, chameleon diamonds regain their greenish color. The nature of the color change remains unclear, but these unique diamonds have a cherished niche among collectors (Fritsch et al., 1995; Hainschwang et al., 2005; Fritsch et al., 2007).

Over the last decade, a few thousand chameleon diamonds have been documented within GIA's laboratories; the vast majority had a stable color that included a green contribution (figure B-1, bottom left). Nearly half were grayish yellow-green, and only about $1 \%$ had pure green hues; $83 \%$ of the chameleons seen at GIA had gray or brown color components as well. Chameleon diamonds were generally smaller than other natural green diamonds (e.g., figure 11), with most weighing less than 1.0 ct (figure B-1, bottom right).
UV fluorescence was a distinctive feature among the chameleon diamonds. Of these, $74 \%$ showed yellow fluorescence and another $18 \%$ exhibited orange or orangy yellow fluorescence in response to long-wave UV exposure. The intensity of the long-wave fluorescence was predominantly strong $(92 \%)$. Under short-wave UV illumination, $86 \%$ showed yellow fluorescence and another $13 \%$ exhibited orange or orangy yellow fluorescence. The intensity of the short-wave UV fluorescence was predominantly medium (85\%). Additionally, all the chameleon diamonds exhibited short-wave UV phosphorescence that was usually weak in intensity (54\%) and yellow in color $(96 \%)$.

GIA laboratory reports include a special comment indicating the unique color-change property of a chameleon diamond. To receive this comment on a report, a diamond must have a green color component (either primary or secondary), it must display phosphorescence to short-wave UV light, and it must change color from greenish to yellow or orange upon gentle heating or removal from light. Tremendous caution must be taken when heating green diamonds, as those colored by GR1 defects may permanently lose some or all of their green color. While chameleon diamonds cross the boundary between green and yellow stones, they remain an interesting oddity that accentuates the novelty of green diamonds.

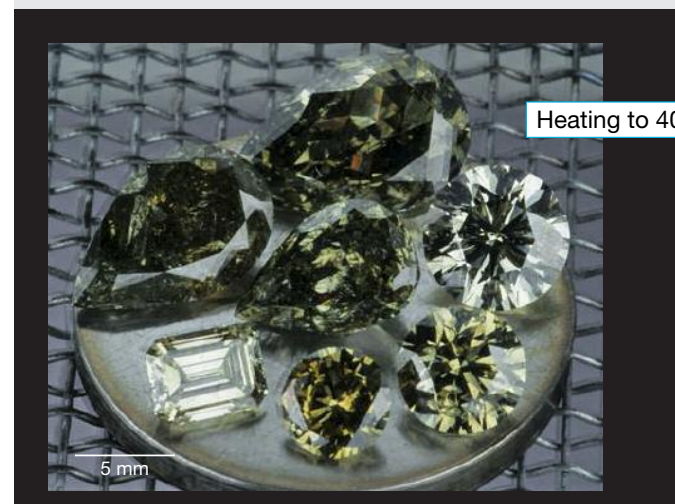

Stable (graded) chameleon colors
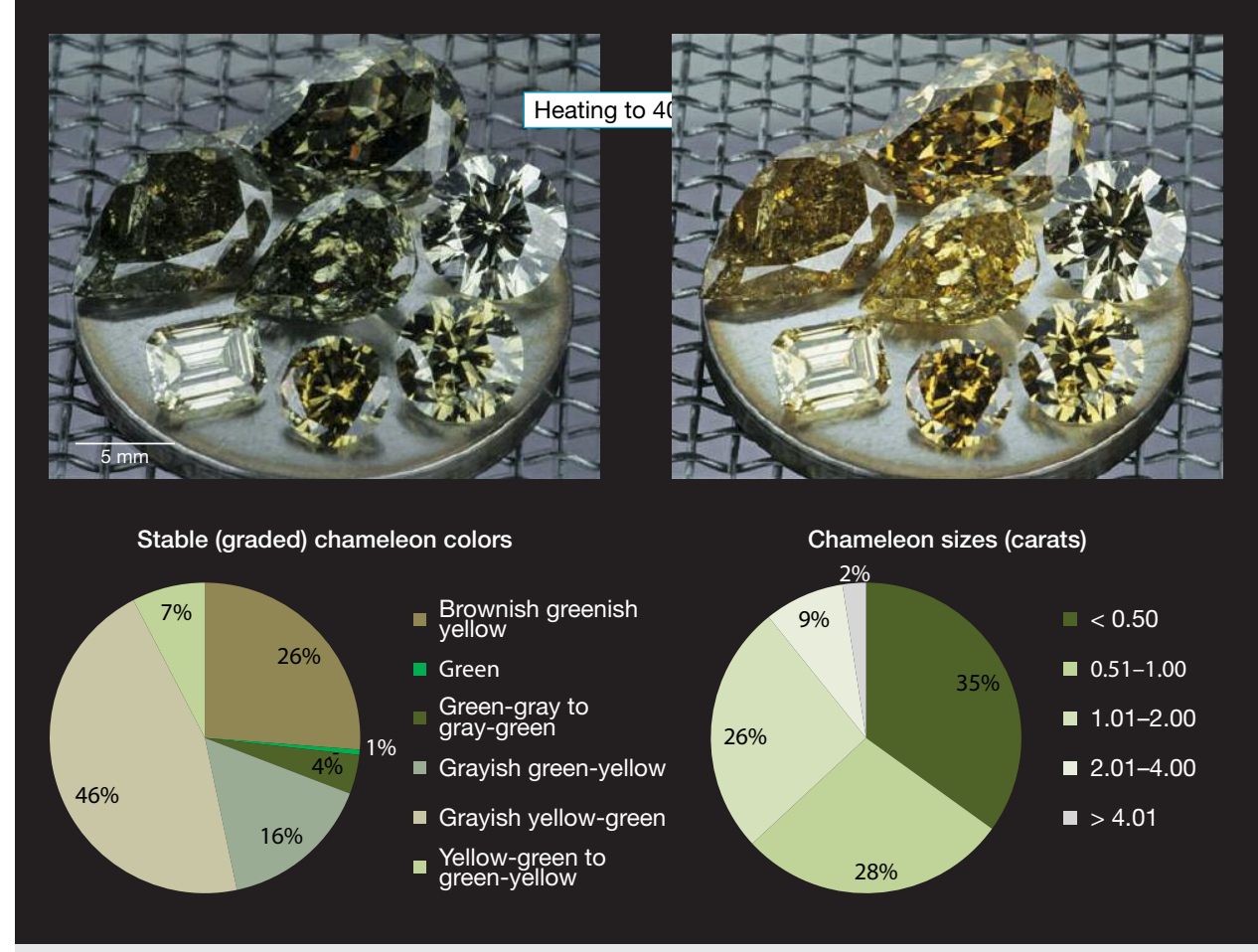

Figure B-1. Chameleon diamonds (top) change from a greenish color to a yellow or orange hue when heated or kept in the dark. Of the chameleon diamonds seen at GIA over the last decade (bottom), most have stable colors of grayish yellow-green and brownish greenish yellow and less than $0.5 \mathrm{ct}$ in size. Photos by C.M. Breeding. 

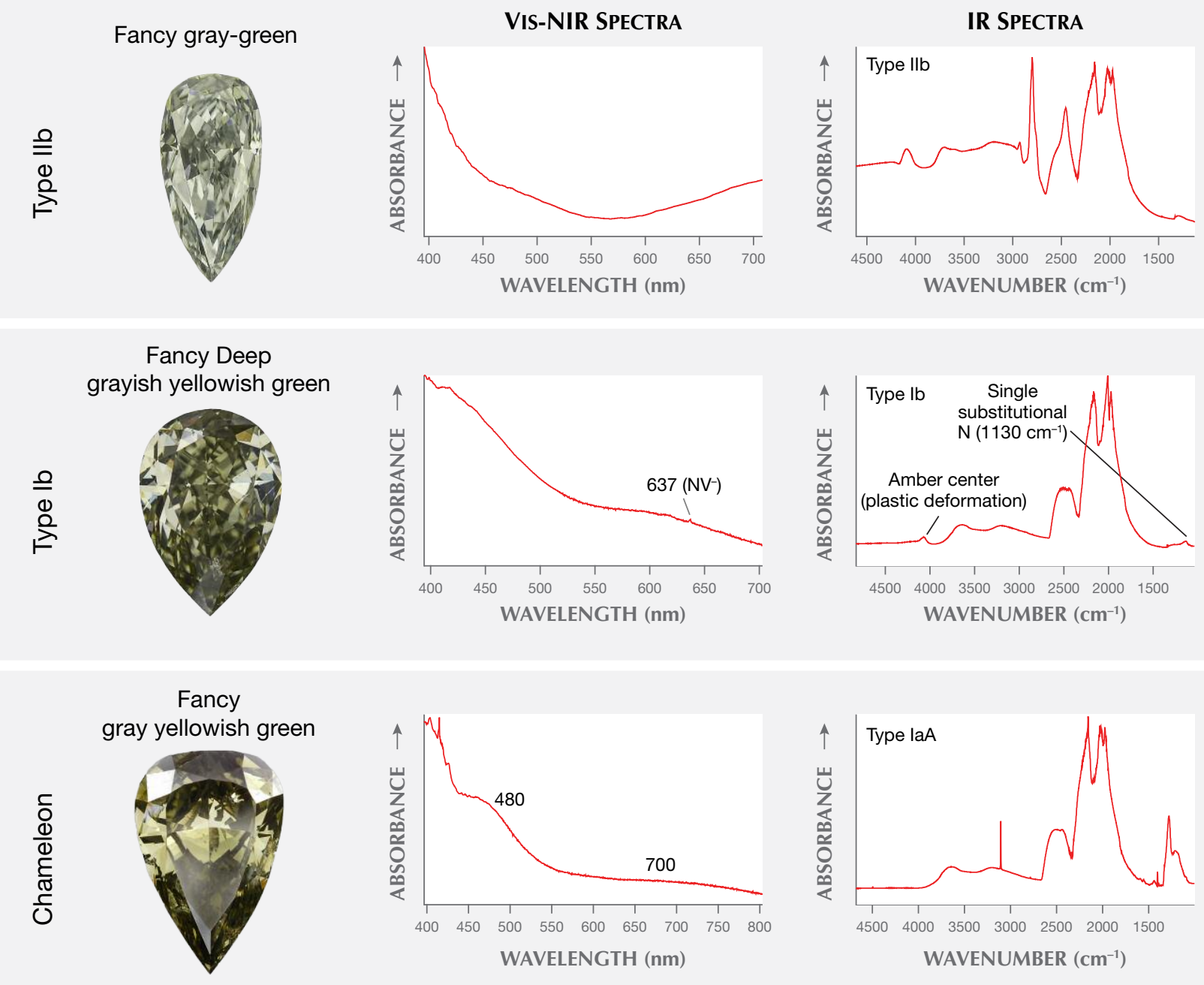

Figure 21. While the vast majority of green diamonds fall into the four categories described in this article, a few very unusual stones with green hues are type IIb, type Ib, or chameleon stones. These very rare diamonds have distinctive spectroscopic features that make them relatively easy to spot.

criteria are considered proprietary information to protect the integrity of GIA's grading report service. To support our conclusion on color origin, dealers sometimes bring an important rough green diamond for us to examine before manufacturing and then during several stages of the process. This allows us to study the progression of the color appearance of the cut stone, and to confirm that it originated from the starting piece of rough.

\section{UNUSUAL EXAMPLES}

We have discussed the four major causes of green color in gem diamonds. These are responsible for some $95 \%$ of the naturally green diamonds seen at
GIA's laboratories in the last decade. As with anything natural, there are a few unusual diamonds with green color components that do not fall within the aforementioned groups. These include type IIb and Ib stones as well as chameleon diamonds (figure 21 and box B). Type IIb diamonds are typically blue due to boron impurities that absorb light from the infrared all the way through the visible spectrum, with the absorption higher at the red end of the spectrum than the blue end. In a few extremely rare cases, a type IIb diamond also has strong absorption from 400 to $500 \mathrm{~nm}$, resulting in a green hue (Crowningshield, 1965; Scarratt, 1989). The cause of the higher-energy absorption is unclear, but it might be elevated trace 


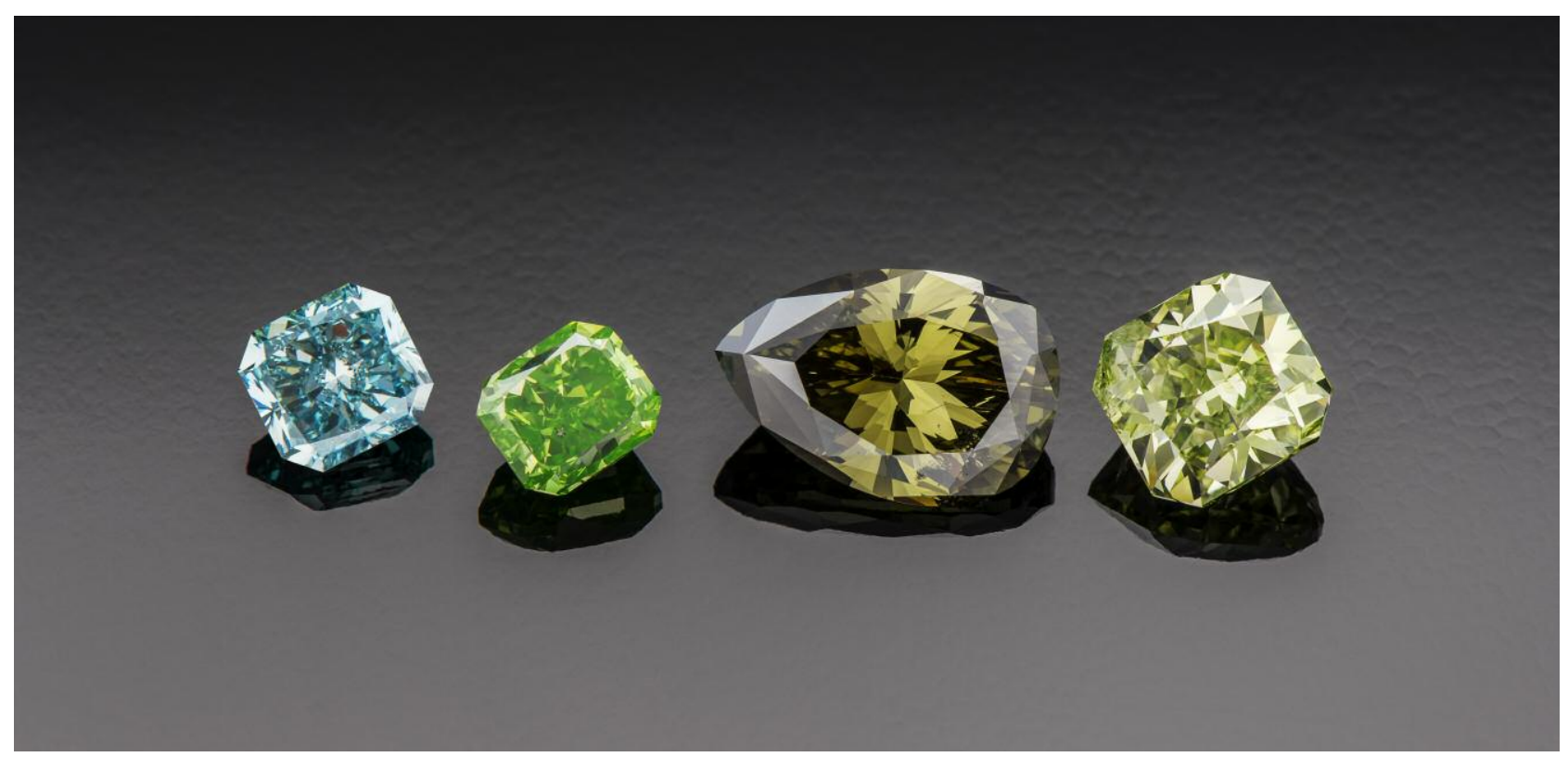

Figure 22. Natural-color green diamonds such as these beautiful gems span a range of colors. From left to right: Fancy Vivid green-blue (2.06 ct), Fancy Vivid yellow-green (1.01 ct), Fancy Dark gray-greenish yellow (3.08 ct), and Fancy Intense yellow-green (2.01 ct). Each of the four main color-causing mechanisms usually produces slightly different green hues. Photo by Robert Weldon/GIA, courtesy of Optimum Diamonds.

concentrations of nitrogen impurities that are masked in the IR by the excessive boron. Type Ib diamonds contain single substitutional nitrogen impurities that absorb strongly in the UV to blue part of the spectrum, generating a strong yellow color. If a type $\mathrm{Ib}$ diamond is plastically deformed and has enough vacancies to increase the $\mathrm{NV}^{-}(637 \mathrm{~nm})$ defect concentration significantly enough to absorb light in the red region, the stone has a greenish hue (usually also grayish or brown from the plastic deformation vacancy cluster absorption, causing a rise to higher energies). The last and perhaps most abundant and interesting oddity is the chameleon diamond (box B). Chameleons are type IaA diamonds (usually with moderate $\mathrm{N}$ content) that exhibit broad $480 \mathrm{~nm}$ (unknown structure) and $700 \mathrm{~nm}$ (H- or Ni- related) bands in the visible spectrum that often give rise to a greenish hue (usually brownish or grayish and termed "brackish"). These popular color-changing collectors' stones occupy their own niche in the diamond trade.

\section{CONCLUSIONS}

Natural-color green diamonds (figure 22) are rare and beautiful, with a variety of defects that can be re- sponsible for their color. Today, most are discovered in South American or African mines. The main causes of green color in gem diamonds, either as the sole mechanism or in combination, are vacancies produced by radiation damage (GR1), H3 defects, $\mathrm{H}$ related defects, or $\mathrm{Ni}$ impurities. Each of these gives rise to a slightly different green hue. GR1-colored green diamonds are most abundant, followed by those colored by $\mathrm{H} 3$ green luminescence. $\mathrm{H}$ - and $\mathrm{Ni}$ related green stones are less common. Each group of green color centers displays gemological clues as well as absorption and luminescence spectra that aid in their identification. Both GR1 and H3 defects can be easily induced in diamond by laboratory irradiation and annealing, a process that has been applied since the 1950s. GIA has made significant progress in determining the origin of color of green diamonds since the 1950s and '60s, when the vast majority were described as undetermined. Today, most green diamonds have a definitive origin determination. Due to the similarities between natural radiation damage and laboratory treatment effects, color origin determinations of green diamonds are not always possible and have turned these rare and exquisite gemstones into the beautiful conundrum they are. 
ABOUT THE AUTHORS

Dr. Breeding and Dr. Eaton-Magaña are senior research scientists, and Dr. Shigley is a distinguished research fellow, at GIA in

Carlsbad, California.
ACKNOWLEDGMENTS

The authors wish to thank the Natural History Museum of Los An geles County and Optimum Diamonds (New York) for allowing us to photograph pieces from the Gamma Collection for this article.

\section{REFERENCES}

Anderson B.W. (1943a) Absorption and luminescence in diamond - I. The Gemmologist, Vol. 12, No. 138, pp. 21-22.

(1943b) Absorption and luminescence in diamond - II. The Gemmologist, Vol. 12, No. 139, pp. 25-27.

(1943c) Absorption and luminescence in diamond - III. The Gemmologist, Vol. 12, No. 141, pp. 33-35.

Ardon T. (2013) Lab Notes: Diamond with high concentration of nickel. Gせ) G, Vol. 49, No. 3, pp. 173-174.

Astric H., Astric B., Merigoux H., Zecchini P. (1994) Evaluation de la masse de Dresde Vert par calcul. Revue de Gemmologie a.f.g., No. 120, pp. 13-14.

Bokii G.B., Bezrukov G.N., Klyuev Y.A., Naletov A.M., Nepsha V.I. (1986) Natural and Synthetic Diamonds. Nauka, Moscow, p. 31 [in Russian].

Bosshart G. (1989) The Dresden Green. Journal of Gemmology, Vol. 21, No. 6, pp. 351-362, http://dx.doi.org/10.15506/ JoG.1989.21.6.351

(1994) Investigations modernes du diamant vert de Dresden et interpretation des resultats. Revue de Gemmologie a.f.g., No. 121, pp. 5-12.

Breeding C.M. (2011) Hydrogen-rich diamonds from Zimbabwe with natural radiation features. $G \uplus G$, Vol. 47, No. 2, pp. 129130.

Breeding C.M., Shigley J.E. (2009) The "type" classification system of diamonds and its importance in gemology. $G \uplus G$, Vol. 45, No. 2, pp. 96-111, http://dx.doi.org/10.5741/GEMS.45.2.96

Breeding C.M., Shen A.H., Eaton-Magaña S., Rossman G.R., Shigley J.E., Gilbertson A. (2010) Developments in gemstone analysis techniques and instrumentation during the 2000s. Gせ G, Vol. 46, No. 3, pp. 241-257, http://dx.doi.org/10.5741/ GEMS.46.3.241

Chaves M.L.S.C., Karfunkel J., Banko A., Stasiulevicius R., Svisero D.P. (1996) Diamantes de capa verde: Freqüência, distribuição e possível origem nos depósitos diamantiferos de Minas Gerais. Boletim Instituto de Geociências - Universidade de São Paulo, Vol. 27, pp. 51-60.

Chaves M.L.S.C., Karfunkel J., Stasiulevicius R., Brandao P.R.G., Chambel L. (2001) Discussão sobre a natureza das cores verde e marrom (em "capas" ou "verdadeiras") em diamantes do SEBrasil (Minas Gerais) e NE-Angola (Lunda). Revista Brasileira de Geociencias, Vol. 31, No. 4, pp. 575-582.

Coenraads R.R., Webb G., Sechos B. (1994) Alluvial diamond deposits of the Guaniamo Region, Bolivar State, Venezuela. Australian Gemmologist, Vol. 18, No. 9, pp. 287-294.

Collins A.T. (1997) The electronic and optical properties of diamond. In A. Paoletti and A. Tucciarone, Eds., The Physics of Diamond. Course 135, Proceedings of the International School of Physics, IOS Press, Amsterdam, p. 273.

- (1999) Things we still don't know about optical centres in diamond. Diamond and Related Materials, Vol. 8, No. 8-9, pp. 1455-1462, http://dx.doi.org/10.1016/S0925-9635(99)00013-8

- 2001) The colour of diamond and how it may be changed. Journal of Gemmology, Vol. 27, No. 6, pp. 341-359, http://dx.doi.org/10.15506/JoG.2001.27.6.341

Collins A.T., Kanda H., Kitawaki H. (2000) Colour changes produced in natural brown diamonds by high-pressure, high-temperature treatment. Diamond and Related Materials, Vol. 9, No. 2, pp. 113-122, http://dx.doi.org/10.1016/S0925-9635(00)00249-1

Crowningshield R. (1965) Developments and highlights at the Gem Trade Lab in New York. GÆ G, Vol. 11, No. 11, pp. 331338.

DeMarco A. (2016) "Aurora Green" diamond sells for record breaking \$16.8 million. Forbes.com, https://www.forbes.com/ sites/anthonydemarco/2016/05/31/aurora-green-diamondsells-for-record-breaking-16-8-million/

Dischler B. (2012) Handbook of Spectral Lines in Diamond, Volume 1: Tables and Interpretations. Springer-Verlag, Berlin.

Draper T. (1951) The diamond mines of Diamantina - Past and present. Get G, Vol. 7, No. 2, pp. 49-57.

Eaton-Magaña S.C., Breeding C.M. (2016) An introduction to photoluminescence spectroscopy for diamond and its applications in gemology. $G \uplus G$, Vol. 52, No. 1, pp. 2-17, http://dx.doi.org/ 10.5741/GEMS.52.1.2

Eaton-Magaña S.C., Moe K.S. (2016) Temperature effects on radiation stains in natural diamonds. Diamond and Related Materials, Vol. 64, pp. 130-142, http://dx.doi.org/10.1016/j. diamond.2016.02.009

Ehrmann M. (1950) Bombarded diamonds. GÆ G, Vol. 6, No. 10, pp. 295-297.

Fisher D. (2009) Brown diamonds and high pressure high temperature treatment. Lithos, Vol. 112S, pp. 619-624, http://dx.doi.org/ 10.1016/j.lithos.2009.03.005

Fritsch E., Shigley J.E. (1991) Optical properties of some naturalcolor and laboratory-irradiated green to blue diamonds. In R. Messier, J.T. Glass, J.E. Butler, and R. Roy, Eds., Proceedings of the Second International Conference-New Diamond Science and Technology, Washington DC, September 23-27, 1990. Materials Research Society, Pittsburgh, Pennsylvania, pp. 677-681.

Fritsch E., Shigley J.E., Moses T., Rossman G.R., Zucker B., Balfour I. (1995) Examination of the twenty-two carat green chameleon diamond. In D.J. Content, Ed., A Green Diamond: A Study of Chameleonism. W.S. Maney \& Son, Leeds, England, 42 pp.

Fritsch E., Massi L., Rossman G.R., Hainschwang T., Jobic S., Dessapt R. (2007) Thermochromic and photochromic behavior of "chameleon" diamonds. Diamond and Related Materials, Vol. 16, No. 2, pp. 401-408, https://doi.org/10.1016/j. diamond.2006.08.014

Goss J.P., Briddon P.R., Hill V., Jones R., Rayson M.J. (2014) Identification of the structure of the $3107 \mathrm{~cm}^{-1} \mathrm{H}$-related defect in diamond. Journal of Physics: Condensed Matter, Vol. 26, No. 14, pp. 1-6, http://dx.doi.org/10.1088/0953-8984/26/14/145801

Guo J.Q., Chen F., Den H.X., Tan Y.M., Rong Z.Q., Den E. (1986) The colour of placer diamonds in Hunan. Acta Mineralogica Sinica, Vol. 6, No. 2, pp. 132-138.

Hainschwang T., Simic D., Fritsch E., Deljanin B., Woodring S., DelRe N. (2005) A gemological study of a collection of chameleon diamonds. $G \uplus G$, Vol. 41, No. 1, pp. 20-35, http://dx.doi.org/10.5741/GEMS.41.1.20

Hough E. (1913) The great green diamond. Metropolitan Magazine, Vol. 38, No. 1, pp. 9-13, 69. 
Kane R.E. (1979a) Developments and Highlights at GIA's Lab in Los Angeles: Green graining. Gせ G, Vol. 16, No. 7, p. 210.

(1979b) Developments and Highlights at GIA's Lab in Los Angeles: Radiation stains. Ge G, Vol. 16, No. 7, p. 211

Kane R.E., McClure S.F., Menzhausen J. (1990) The legendary Dresden Green diamond. $G \uplus G$, Vol. 26, No. 4, pp. 248-266, http://dx.doi.org/10.5741/GEMS.26.4.248

Koptil V.I., Zinchuk N.N. (2000) A change in diamond properties induced by natural radioactive irradiation. Journal of Superhard Materials, Vol. 22, No. 2, pp. 56-57.

Luo Y., Breeding C.M. (2013) Fluorescence produced by optical defects in diamond: Measurement, characterization, and challenges. GÆ G, Vol. 49, No. 2, pp. 82-97, http://dx.doi.org/ 10.5741/GEMS.49.2.82

Massi L., Fritsch, E., Collins A.T., Hainschwang T., Notari F. (2005) The "amber centres" and their relation to the brown colour in diamond. Diamond and Related Materials, Vol. 14, No. 10, pp. 1623-1629, http://dx.doi.org/10.1016/j.diamond.2005.05.003

Mendelssohn M.J., Milledge H.J., Vance E.R., Nave E., Woods P.A. (1979) Internal radioactive haloes in diamond. Diamond Research, Vol. 17, No. 2, pp. 21-26.

Mennell F.P. (1915) Note on the colours of some alluvial diamonds. Mineralogical Magazine, Vol. 17, No. 81, pp. 202-204, http://dx.doi.org/10.1180/minmag.1915.017.81.07

Meyer H.O.A., Milledge H.J., Nave E. (1965) Natural irradiation damage in Ivory Coast diamonds. Nature, Vol. 206, No. 4982, p. 392, http://dx.doi.org/10.1038/206392a0

Miller J. (2011) U.S. sanctions prohibit trade with Zimbabwe's diamond entities. Diamonds.net, Nov. 2, http://www.diamonds.net/News/NewsItem.aspx? ArticleID $=37681$

Morel B. (1994) La veritable histoire du diamant vert de Dresden. Revue de Gemmologie a.f.g., No. 121, pp. 2-3.

Nasdala L., Grambole D., Wildner M., Gigler A.M., Hainschwang T., Zaitsev A.M., Harris J.W., Milledge J., Schulze D., Hofmeister W., Balmer W.A. (2013) Radio-colouration of diamond: A spectroscopic study. Contributions to Mineralogy and Petrology, Vol. 165, No. 5, pp. 843-861, http://dx.doi.org/10.1007/s00410-0120838-1

Raal F.A., Robinson D.N. (1981) Research into green diamonds. Diamond News and S.A. Jeweller, Vol. 44, No. 6, pp. 47-53.

Rondeau B., Fritsch E., Guiraud M., Chalain J.-P., Notari F. (2004) Three historical 'asteriated' hydrogen-rich diamonds: Growth history and sector-dependent impurity incorporation. Dia- mond and Related Materials, Vol. 13, No. 9, pp. 1658-1673, http://dx.doi.org/10.1016/j.diamond.2004.02.002

Rosch S. (1957) Das Grune Gewölbe in Dresden. Zeitschrift der Deutschen Gesellschaft fur Edelsteinkunde, Sonderheft, pp. 79-84.

Roskin G. (2000) Provenance of a green diamond. Jewelers' Circular Keystone, Vol. 171, No. 9, pp. 158-169.

Scarratt K. (1989) Naturally coloured green type IIb diamond. Journal of Gemmology, Vol. 21, No. 6, p. 346.

Shigley J.E., Breeding C.M. (2013) Optical defects in diamond: A quick reference chart. $G \uplus G$, Vol. 49, No. 2, pp. 107-111, http://dx.doi.org/10.5741/GEMS.49.2.107

Shigley J.E., Fritsch E. (1990) Optical properties of some greenish blue to green diamonds. SPIE Proceedings, Vol. 1325, pp. 315324.

Themelis T. (1987) Diamonds from Venezuela. Lapidary Journal, Vol. 41, No. 4, pp. 59-64.

Titkov S.V., Ivanov A.I., Marfunin A.S., Bershov L.V., Kulakov V.M., Chukichev M.V. (1995) Irradiation as the cause of the bulk green color in natural diamonds. Doklady Earth Sciences, Vol. 337, No. 5, pp. 133-138.

Vance E.R., Milledge H.J. (1972) Natural and laboratory $\alpha$-particle irradiation of diamond. Mineralogical Magazine, Vol. 38, No. 299, pp. 878-881, http://dx.doi.org/10.1180/minmag.1972.038.299.11

Vance E.R., Harris J.W., Milledge H.J. (1973) Possible origins of $\alpha$ damage in diamonds from kimberlite and alluvial sources. Mineralogical Magazine, Vol. 39, No. 303, pp. 349-360, http://dx.doi.org/10.1180/minmag.1973.039.303.12

Wang W., Mayerson W. (2002) Symmetrical clouds in diamond the hydrogen connection. Journal of Gemmology, Vol. 28, No. 3, pp. 143-152, http://dx.doi.org/10.15506/JoG.2002.28.3.143

Wang W., Hall M., Breeding C.M. (2007) Natural type Ia diamond with green-yellow color due to Ni-related defects. $G \uplus G$, Vol. 43, No. 3, pp. 240-243, http://dx.doi.org/10.5741/GEMS 43.3.240

Welbourn C.M., Cooper M., Spear P.M. (1996) De Beers natural versus synthetic diamond verification instruments. $G \uplus G$, Vol. 32, No. 3, pp. 156-169, http://dx.doi.org/10.5741/GEMS.32.3.156

Woods G.S. (1986) Platelets and the infrared absorption of type Ia diamonds. Proceedings of the Royal Society A, Vol. 407, No. 1832, pp. 219-238, http://dx.doi.org/10.1098/rspa.1986.0094

Zaitsev A.M. (2003) Optical Properties of Diamond: A Data Handbook. Springer-Verlag, Berlin.

\section{For online access to all issues of GEMS \& GEMOLOGY from 1934 to the present, visit:}

